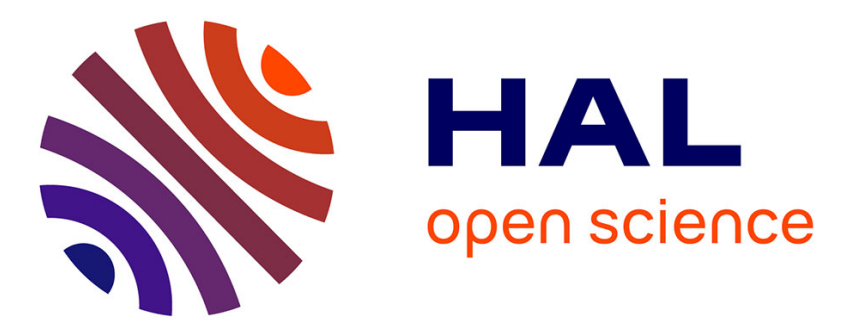

\title{
Relationship between Stereochemistry and Charge Density in Hydrogen Bonds with Oxygen Acceptors
}

\author{
M. Ahmed, Christian Jelsch, B. Guillot, C. Lecomte, S. Domagala
}

\section{To cite this version:}

M. Ahmed, Christian Jelsch, B. Guillot, C. Lecomte, S. Domagala. Relationship between Stereochemistry and Charge Density in Hydrogen Bonds with Oxygen Acceptors. Crystal Growth \& Design, 2012, 13 (1), pp.315-325. 10.1021/cg3014656 . hal-01719267

\section{HAL Id: hal-01719267 \\ https://hal.science/hal-01719267}

Submitted on 28 Feb 2018

HAL is a multi-disciplinary open access archive for the deposit and dissemination of scientific research documents, whether they are published or not. The documents may come from teaching and research institutions in France or abroad, or from public or private research centers.
L'archive ouverte pluridisciplinaire HAL, est destinée au dépôt et à la diffusion de documents scientifiques de niveau recherche, publiés ou non, émanant des établissements d'enseignement et de recherche français ou étrangers, des laboratoires publics ou privés. 
Cryst. Growth Des., 2013, 13 (1), pp 315-325

DOI: $10.1021 / \mathrm{cg} 3014656$

Publication Date (Web): November 27, 2012

\title{
Relationship between stereochemistry and charge density in hydrogen bonds with oxygen acceptors
}

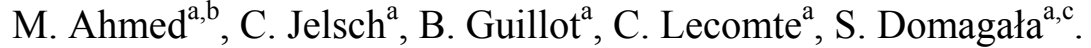 \\ ${ }^{a}$ Cristallographie, Résonance Magnétique et Modélisations, CNRS UMR 7036, \\ Université de Lorraine. Vandoeuvre-les-Nancy, France. \\ ${ }^{b}$ Dept. of Chemistry, Material Chemistry Lab, Government College University, Lahore, Pakistan. \\ ${ }^{\mathrm{c}}$ Warsaw University, Chemistry Department, Poland. \\ E-mail : christian.jelsch@univ-lorraine.fr
}

\section{Summary}

An extensive survey of Cambridge Structural Database is carried out to study the directionality and stereochemistry of hydrogen bonds with an oxygen acceptor including carbonyl, alcohols, phenols, ethers and esters groups. The results obtained through this survey are correlated with the charge density of these different chemical groups. The electron density of these different oxygen atoms types show striking dissimilarities in the electron lone pairs configuration. Esters and ethers with the C-O-C oxygen atom located in an aromatic cycle display merged lone pairs lobes which is not the case when one of the bonded carbon atom has $\mathrm{sp}^{3}$ hybridization.

The positions of the lone pairs in the deformation electron density maps derived from theoretical calculation and from experimental charge density generally agree with the notable exception of phenols and $\mathrm{C}\left(\mathrm{sp}^{3}\right)$ esters. The experimental studies show generally lone pairs lobes which are closer to each other.

Differences are found within $\mathrm{COH}$ groups: the two electron lone pairs are slightly closer in phenol oxygen atoms compared to alcohols in theoretical electron densities. In experimental charge densities, 
the discrepancy is more drastic as the two lone pairs lobes appear merged in phenols; this might be due to a resonance effect with the neighbor $\mathrm{sp}^{2}$ carbon atom. This difference in the configuration of the two electron lone pairs affects the directionality of hydrogen bonds. For phenols, the preferred donor hydrogen atom position is close to the $\mathrm{COH}$ plane, while for alcohols it is out of plane with the direction $\mathrm{O} \ldots \mathrm{H}_{\text {donor }}$ forming an angle of around $30^{\circ}$ to the $\mathrm{COH}$ plane.

The number of H-bonds occurring with the donor hydrogen atom pointing towards the middle of the two lone pairs is small for carbonyl, contrary to alcohols and phenols. Also H-bonds involving alcohol/phenol acceptors have a stronger tendency to occur in directions close to the electron lone pairs plane than for carbonyl. As expected, the directional attraction of hydrogen bond donors towards the lone pairs is much more pronounced for short H...O distances. This study could have implications in the design of force fields, in molecular recognition, supramolecular crystal engineering and drug design. 


\section{Introduction}

Hydrogen bonds are ubiquitous in biological and organic molecules and are vital to the structure and functioning of a large majority of biological and chemical systems. A thorough understanding of the stereochemistry and relative strength of hydrogen bonds is essential in designing novel drug molecules, supramolecular materials and engineering of specific crystal structures ${ }^{1,2}$. In drug design, the coordinates of the hydrogen bond acceptor and donor atoms in protein-ligand binding sites indicate the positions at which it would be advantageous to place the complementary atoms of the novel drug molecules. The knowledge of hydrogen bonds stereo-chemical rules is also required as constraints for molecular graphics algorithms used for docking studies ${ }^{3}$ and for prediction of hydrogen-bonding propensity in organic crystals ${ }^{4}$.

Nitrogen and oxygen are the most common and strongest hydrogen bond acceptors. Their prevalence in biological molecules and other chemical groups requires that their propensity as hydrogen bond acceptor be investigated. To this end, it is needed that the stereochemistry of the hydrogen bonds is studied and that general trends are evaluated. This study focuses on the directionality of hydrogen bonds when oxygen is involved as acceptor.

The directionality of the hydrogen bonds to date is still a matter of debate. An initial study of the OH...O hydrogen bonds was made by Kroon et al. (1975) ${ }^{5}$ and was followed by Ceccarelli et al (1981) 6 , but they could not find a significant correlation between the geometries of the hydrogen bonds and the direction of oxygen $\mathrm{sp}^{3}$ lone pairs (LPs).

The very first study of the electron density of oxygen atoms involved in different types of $\mathrm{H}$ bonds was made by Olovsson $(1982)^{7}$ which stated that the experimental deformation density (no multipolar refinement) in water molecules and hydroxyl groups is usually found as one broad peak extending over a large part of the lone pairs region. In contrast, the lone pair deformation density in $\mathrm{C}=\mathrm{O}$ groups is generally resolved into two distinct lobes, in the directions approximately expected for $\mathrm{sp}^{2}$ hybridization.

On the basis of the Olovsson's findings, Taylor et al. ${ }^{8,9} \& 10$ analyzed hydrogen bonding by making a survey of the 1509 crystal structures deposited at that time in the Cambridge Structural Database (CSD). They used H-X bond distances normalized to average neutron diffraction distances and stated 
that the lone pair deformation electron density is resolved into two distinct maxima in the direction of $\mathrm{sp}^{2}$ lone pairs and that the majority of the hydrogen bonds tended to be found near the plane of the lone pairs within an angle of $12.84^{\circ}$ above and below the plane. However these studies were limited to a smaller number of structures as compared to the available structures in the present CSD. They also concluded that "the directional influence of $\mathrm{sp}^{3}$ lone pairs is less important than that of $\mathrm{sp}^{2}$ lone pairs" and they presumed it necessary to use much larger sample of hydrogen bond to establish whether $\mathrm{sp}^{3}$ lone pairs have a significant "directional influence" in the crystalline state.

In general, there are four main sources by which the information about hydrogen bonds can be obtained. These are NMR solution studies, infra-red spectroscopies, computational studies and statistical analysis of crystal structures. A very reliable, systematic, and commonly used method to scrutinize hydrogen bonding is to survey crystal structures studied so far.

The two main crystal structure databases are the Brookhaven Protein Databank (PDB) ${ }^{11}$ and the Cambridge Structural Database (CSD). The Cambridge Structural Database (CSD) is a repository of the crystal structures studied by X-rays and neutron crystallography ${ }^{12}$. The entries in the Protein Databank consist of crystal structures of proteins, nucleic acids and viruses. The vast majority of these structures are however not at atomic resolution $(d<1 \AA)$ and the electron density maps do not allow the position of hydrogen atoms to be seen. On the other hand, the Cambridge Structural Database is a repository of small and medium sized molecules. The version 5.32 of the CSD (August 2011) contains around 525,095 entries studied by X-ray and Neutron Diffraction. CSD has built in tools like ConQuest $^{13}$, VISTA ${ }^{14}$ and Mercury ${ }^{15}$ which have made the survey of the database very practical. There have been several studies carried out on the directionality of hydrogen bonding using the CSD. The $\alpha$ and $\beta$ angles used to describe the $\mathrm{H}$-bonds geometry throughout this study are represented in Figs. 1 and 2 for $\mathrm{sp}^{2}$ and $\mathrm{sp}^{3}$ oxygen atoms, respectively.

A very extensive investigation was done by Mills \& Dean ${ }^{3}$ who studied the 3D geometry of several hydrogen bond acceptors and donors. The relative propensity of the groups to form a hydrogen bond was also estimated. The Mills \& Dean analysis ${ }^{3}$ can be used to predict the potential site points where a ligand could interact.

Generally for $\mathrm{sp}^{2}$ carbonyl oxygen acceptors, hydrogen bonding occurs in the direction of the lone pairs forming two separate lobes at angles of $\pm 60^{\circ}$ with the $\mathrm{C}=\mathrm{O}$ direction ${ }^{16}$. 
The angular distribution and directionality of the hydrogen bonding with $\mathrm{sp}^{2} \mathrm{C}=\mathrm{O}$ oxygen (ketones, esters) and $\mathrm{sp}^{3}$ oxygen (C-O-C ethers, epoxides) acceptors were analyzed by Rust $\&$ Glusker ${ }^{17}$. In all systems, the largest concentration of hydrogen-bonds lay in the direction commonly ascribed to lone pairs. The distribution of hydrogen donor around the epoxide oxygen resembles to that in ketones with two resolved zones in the directions of the lone pairs. There are two local concentrations of hydrogen donor density which are out of the C-O-C plane of the epoxide. On the contrary, for ether oxygen atoms, the hydrogen donor distribution is more smeared and has a "banana" shape. The hydrogen bonds occur uniformly around the oxygen atom between the two lone pairs but their distribution is more concentrated around the C-O-C plane. Therefore, these authors postulated that the LP-O-LP' angle formed by the lone pairs is larger in epoxides than in ethers.

Hay et al. ${ }^{18}$ have studied the directionality of hydrogen bonds in tetrahedral oxyanions like $\mathrm{NO}_{3}, \mathrm{PO}_{4}{ }^{3-}$ , $\mathrm{SO}_{4}{ }^{2-}$ through the survey of the $\mathrm{CSD}$ and studying the electrostatic potential using Density Functional Theory calculations. They have concluded that the average $\mathrm{H} \cdots \mathrm{O}-\mathrm{X}$ angle is $122^{\circ}$ and there is a weak but observable preference for hydrogen atoms to adopt an eclipsed conformation with respect to the $\mathrm{H} \cdots \mathrm{O}-\mathrm{A}-\mathrm{O}$ dihedral angles. Their study finds potential use in the development of receptors which can be selective inorganic oxyanions.

A comparative study on the geometry and directionality of hydrogen bonding with sulphur acceptor in thiourea, thioamides and thiones and with $\mathrm{O}$ counterparts in urea, amides and ketones was carried out by Wood et al.(2008) ${ }^{16}$. The experimental results were found to be in agreement with ab initio calculations. Remarkable differences in the directionality of the hydrogen bonds were noted for $\mathrm{O}$ and $\mathrm{S}$ acceptors. Notably the $\mathrm{S}=\mathrm{O} \cdots \mathrm{H}_{\mathrm{d}}$ angle ( $\alpha$ angle, Fig. 1) for $\mathrm{S}$ acceptors is around $102-109^{\circ}$ while, for oxygen acceptors, the $\mathrm{C}=\mathrm{O} \cdots \mathrm{H}_{\mathrm{d}}$ angle is around $127-140^{\circ}$. The interaction energy for $\mathrm{S}$ acceptors is consistently lower compared to $\mathrm{O}$ acceptors by an amount of $\sim 12 \mathrm{~kJ} / \mathrm{mol}$.

The interaction energy greatly depends on the H...A distance and angles geometry. A recent dimer based study through a CSD survey and $a b$ initio calculations were performed to investigate effects of $\mathrm{D}-\mathrm{H} \cdots \mathrm{A}$ angle on the database statistics as well as the energy of interaction itself ${ }^{19}$. They found, on the 
basis of the interaction energy, that the strong hydrogen bonds show a smaller range of flexibility in the D-H...A angle than the weak hydrogen bonds.

Through this survey, a statistical analysis of the entries in the CSD was carried out which led to novel conclusions about the trends in molecular geometry and hydrogen bonding which satisfy our anticipations on the basis of the oxygen charge density.

Experimental charge density analysis of the accurate high resolution single crystals X-rays diffraction data is now a mature branch of modern crystallography ${ }^{20}$. With the highly intense X-rays sources and improvements of CCD area detectors, it has become possible to analyze the electron density in its finest details. Charge density is a physically observable quantity and hence it can be used to analyze a number of problems of chemical ${ }^{21}$ and physical $^{22}$ interest in biological ${ }^{23}$, organic or inorganic systems $24,25,26 \& 27$. The importance of charge density studies is clear from the Hohenherg-Kohn theorem ${ }^{28}$ which states that the electron density distribution of a molecule uniquely describes all the ground state properties."

The ELMAM library describing the electron density of common chemical groups was developed in our laboratory $^{29,30}$. The library is built from accurate ultra high resolution crystallographic studies of a sample of peptides and small molecules. The library contains a wealth of information about the features of electron density of many organic chemical groups. It was observed in the database that the alcohol Csp ${ }^{3}-\mathrm{O}-\mathrm{H}$ and phenol $\mathrm{Csp}^{2}-\mathrm{O}-\mathrm{H}$ groups display different deformation electron densities. The electron lone pairs showed merged lobes in the first version of ELMAM experimental database ${ }^{29}$ and nearly merged lobes in the revised version ELMAM2 ${ }^{30}$. The merging of the two LP lobes was also observed in an experimental charge density analysis of a paracetamol, compound containing a phenol group $^{31}$. The database contains also other oxygen atom types (carbonyl, ester, ether, nitro) which also display different lone pairs orientations in the electron density. Therefore, we decided to investigate the hydrogen directionality pattern of these various oxygen acceptors as the lone pairs are known to attract hydrogen donors ${ }^{17}$. 
The comparison of the directionality of hydrogen bonds with respect to phenol and alcohol acting as acceptor has never been carried out. There is also a need to update stereochemistry studies of hydrogen bonding with carbonyl oxygen with the larger number of crystal structures available in the CSD. In this study, the crystallographic survey of H-bonds with oxygen acceptor is put in relationship with the charge density distribution of oxygen atoms. The charge density and especially the electron lone pairs of several oxygen atom chemical types were analyzed. The goal is to obtain reliable predictions about the pattern of possible hydrogen bonding from the knowledge of the electron density distribution around the acceptor oxygen atom.

\section{Materials and Methods}

\subsection{Experimental charge densities}

The Hansen and Coppens $(1978)^{32}$ multipolar formalism was used to represent the charge density distribution. This model describes the electron density of an atom as a sum of three different terms.

$$
\rho(\rho)=\rho_{\text {core }}(r)+P_{\text {val }} \kappa^{3} \rho_{\text {val }}(\kappa r)+\sum_{l=0}^{l_{\max }} \kappa^{\prime 3} R_{n_{l}}\left(\kappa^{\prime} r\right) \sum_{m=0}^{l} P_{l m} y_{l m \pm}(\theta, \varphi)
$$

The first two terms represent the core and the valence spherical electron density of the atom. The third term describes the multipolar electron density. $\kappa$ and $\kappa^{\prime}$ stand for the expansion-contraction of the spherical and multipolar valence densities. $P_{\text {val }}$ is the valence shell population, $P_{\operatorname{lm} \pm}$ are the multipole populations. $y_{\mathrm{lm}}$ represent spherical harmonic functions of order $l$ in real form, $R_{n l}$ are Slater type radial functions. Several molecules with oxygen acceptors for which experimental charge density studies were published were selected. The charge density refinements were performed with software $\mathrm{MoPro}^{33}$ using the reflections file with a standard strategy, as described ${ }^{34}$. Optimal local axes systems were used, chemical equivalence and multipoles symmetry constraints were applied, $X Y Z$ coordinates and $U_{\mathrm{ij}}$ thermal parameters of non $\mathrm{H}$ atoms were refined using high order reflections $\left(s>0.7 \AA^{-1}\right)$ only.

\subsection{Theoretical calculations.}


Periodic quantum mechanical calculations using CRYSTAL06 ${ }^{35}$ were performed for a set of compounds containing different oxygen acceptors. The crystal structures analyzed were retrieved from the litterature: thymidine ${ }^{36}$, quercetin monohydrate ${ }^{30}$, orange polymorph of coumarin $314^{37}$, dimethyl ether ${ }^{38}$ and the epoxy compounds mikanolide ${ }^{39}$ and ethylene oxide ${ }^{40}$.

The crystal geometry observed experimentally was used as starting geometry and optimization was performed with density functional theory (DFT) method ${ }^{28}$ and with the B3LYP hybrid functional ${ }^{41,42}$ using 6-31G $(d, p)$ basis set ${ }^{43}$. Upon convergence on energy $\left(\Delta E \sim 10^{-6}\right)$, the periodic wave-function based on the optimized geometry was obtained. Index generation scheme ${ }^{44}$ was applied to generate the unique Miller indices up to $s=1.2 \AA^{-1}$ reciprocal resolution. The option XFAC of the CRYSTAL06 program was then used to generate a set of theoretical structure factors from the computed electron density and using set of prepared indices. Structure factors were calculated up to a resolution of $d=0.4$ $\AA$.

The charge density parameters $\left(P_{\mathrm{val}}, P_{\mathrm{lm} \pm}, \kappa, \kappa^{\prime}\right)$ were subsequently refined using the MoPro package $^{33}$. The scale factor was set to unity, the atomic thermal parameters to zero and the positions kept fixed. The Hansen \& Coppens ${ }^{32}$ multipolar atom model described in equation (1) was used. The $\mathrm{C}, \mathrm{N}, \mathrm{O}$ atoms were modelled up to octapolar level and hydrogen atoms using one dipole and one quadrupole directed along the $\mathrm{H}-\mathrm{X}$ bond axis.

\subsection{Crystallographic database searches}

All crystallographic data were retrieved from the Cambridge Structural Database (CSD Version 5.32). Molecular crystals with different type of oxygen acceptors hydrogen bonded within their crystal packing were searched with program ConQuest (1.12). The $\mathrm{C}\left(\mathrm{sp}^{3}\right)-\mathrm{O}-\mathrm{H}$ alcohols, the $\mathrm{C}_{6} \mathrm{H}_{5} \mathrm{OH}$ phenol, $>\mathrm{C}=\mathrm{O}$ carbonyl groups were searched. The $\mathrm{C}-\mathrm{O}-\mathrm{C}$ oxygen acceptors were differentiated in three groups, depending on the $\mathrm{sp}^{3}$ or $\mathrm{sp}^{3}$ nature of the two carbon atoms. Subsequent statistical analysis and data visualisation was done with VISTA (V 2.1).

The electron density of hydrogen atoms observed in X-ray structures is not centred on the nucleus position. Therefore, the hydrogen atoms in the structures were repositioned according to standard H-X neutron distances ${ }^{45}$, as this option is available in ConQuest software. 
All searches were restricted to the following conditions:

(i) Crystallographic $R$-Factor lower than 0.05 .

(ii) Non-disordered structures.

(iii) No polymeric connections.

(iv) Error free coordinates, as per criterion used by CSD.

(v) Only organic compounds.

(vi) No ionic structure.

Many criteria have been proposed to distinguish the presence of a hydrogen bond. Among these, many were based on a simple distance cut-off. For instance, Rust \& Glusker (1984) ${ }^{17}$ proposed the following criterion: the intermolecular distance between the donor and acceptor atoms D $\cdots \mathrm{O}$ should be less than 3.0 Å. Koch \& Popelier (1995) ${ }^{46}$ have proposed eight criteria based on stereochemistry but also on the topology of the electron density to define hydrogen bonds. Recently, a definition of hydrogen bonding was proposed by Arunan et al. (2011) ${ }^{47}$; there is experimental evidence for its partial covalent nature and the observation of a blue-shift in stretching frequency upon D-H...A hydrogen bond formation. As the CSD gives access to structural features only, this database search is based on the fourth of the Koch \& Popelier criteria which states that the hydrogen...acceptor distance is smaller than the sum of the van der Waals radii. This criterion is practical but not absolute as weak hydrogen bonds can display longer hydrogen...acceptor distances ${ }^{48}$. The values of van der Waals radii are considered to be $1.52 \AA$ for oxygen, $1.55 \AA$ for nitrogen ${ }^{49}$ and $1.09 \AA$ for hydrogen ${ }^{50}$.Only H$\mathrm{N}$ and $\mathrm{H}-\mathrm{O}$ hydrogen bond donors were considered as the current study does not focuses on weak $\mathrm{C}$ $\mathrm{H} \cdots \mathrm{O}$ hydrogen bonds. Thus, the $\mathrm{H} \cdots \mathrm{O}$ interaction hits from the CDS search were discarded as soon as the $\mathrm{H} \cdots \mathrm{O}$ distance was larger than $2.61 \AA$.

\section{Results and Discussion}




\subsection{Lone pairs electron density}

The electronic clouds corresponding to the electron LPs on several types of oxygen atoms are shown in Fig. 3 for the charge density derived from theoretically computed structure factors. The experimental deformation electron densities are also shown in Fig. 4 for the phenol group and for the ester groups (one $\mathrm{sp}^{3}$ and one aromatic) found in coumarin 314 , orange form ${ }^{37}$. The theoretical charge density features show significant differences in the respective orientations of the two LPs and depend on the connectivity and chemical environment of the oxygen atoms. Similar trends can be seen in the maps obtained from experimental charge densities or transferred from the ELMAM2 database ${ }^{29}$. However there are also differences between experiment and theory, the lone pairs lobe are generally closer to each other in the experimental maps, except for the epoxide moiety (Table 1).

The positions of LPs have been investigated by Wiberg et al. $(1994)^{51}$ for several $\mathrm{C}=\mathrm{O}$ groups, water and dimethyl ether. They positioned the LPs at the minimum of $\nabla^{2} \rho$, the Laplacian of the total electron density, while the minimum of electrostatic potential points was also used as an indicator of the LPs geometry. With the Laplacian definition, the LP-O-LP' angles were found in the Wyberg study to be in the $105-111^{\circ}$ range for formaldehyde, $106.9^{\circ}$ for water and $109^{\circ}$ for dimethyl ether.

The lone pairs, as visualized in the deformation of the theoretical electron density (Fig. 3) are the most apart in the epoxy group, in accordance with the postulate of Rust \& Glusker ${ }^{17}$, followed by carbonyl, alcohol, $\mathrm{C}\left(\mathrm{sp}^{3}\right)$ ether, phenol and $\mathrm{C}\left(\mathrm{sp}^{3}\right)$ ester (Table 1$)$. In ethers and esters within aromatic groups, the two lone pairs are so close that the electron density lobes appear as merged. The configurations of the lone pairs show similar trends in experimental charge density studies ${ }^{37}$ and in the ELMAM2 electron density databank. For instance, the electron density of lone pairs was found to be closer in phenols compared to alcohols ${ }^{29,30}$. Fig. 4 shows the experimental electron density of the two ester groups present in coumarin 314 , orange crystal form ${ }^{37}$. The ester oxygen atom within the aromatic cycle shows merged LP lobes, in both experimental and theoretical charge densities. If the two results agree qualitatively, the LPs lobes are however more merged in the experimental map than in the theoretical map, which shows an elongated electron density. The ester involving a $\mathrm{C}\left(\mathrm{sp}^{3}\right)$ carbon atom shows two distinct lobes in the theoretical map but one elongated lobe in the experimental one. The experimental charge density is likely to be accurate, as the thermal motion is very moderate on the oxygen atom $\left(B_{\text {eq }}=1.2 \AA^{2}\right)$ of this ester side chain in C-314 orange crystal form. There is a general 
tendency to observe a systematic discrepancy of the LPs geometry between experiment and theory. It is possible that the basis set employed in the ab-initio calculations is not sufficient for the accurate description of some oxygen atom types, notably phenols.

\subsection{Comparison of alcohols and phenols}

The hydroxyl oxygen atom in alcohols is bonded to $\mathrm{a} \mathrm{sp}^{3}$ carbon atom while in phenols; it is bonded to a $\mathrm{sp}^{2}$ carbon atom. The charge density from the ELMAM2 database ${ }^{30}$ and from theoretically computed electron densities reveal that the LP electron density lobes for the phenol oxygen atom are closer to each other compared to alcohols (Fig. 3). The LPs electron density in alcoholic oxygen displays two distinct lobes, both in experimental and theoretical maps (Fig. 3; Table 1). If the LP positions are taken at the peak maxima in the deformation electron density map, the LP-O-LP' angle for alcohols is found to be $135^{\circ}$ and $106^{\circ}$ for theory and experiment, respectively (Table 1). The experimental lobes configuration is actually not far from a tetrahedral geometry of the oxygen atom.

Compared to alcohols, the LP lobes appear closer to each other for the phenol groups of quercetin in the theoretical maps (Fig. 3a,b) with a LP-O-LP' angle of $109^{\circ}$. In the experimental maps, the configuration is drastically different as the lobes appear merged (Fig. 4). This result was verified in other charge density studies (Fig. S1).

H-bonds to oxygen acceptors have the tendency to form with the hydrogen donor atom $\left(\mathrm{H}_{\mathrm{d}}\right)$ oriented towards one of the LPs, i.e. the triplet O-LP $\cdots \mathrm{H}_{\mathrm{d}}$ tends to be aligned ${ }^{17}$. As a consequence, the hydrogen bonding of the alcohol and phenol oxygen atom types can be expected to display slightly different orientation patterns. The stereochemical feature which differs strikingly between the two groups is the $\alpha$ angle (Fig. 1 and 2), which is the angle between the $\mathrm{O} \cdots \mathrm{H}_{\mathrm{d}}$ direction and the $\mathrm{COH}$ plane.

When the two chemical groups are compared within the CSD search, it is indeed observed that the phenol group shows a greater tendency for the hydrogen bonds to be situated close to the $\mathrm{COH}$ plane ( $\alpha$ closer to zero, Fig. 5). This is to be related to the electron lone pairs configuration which are located at a smaller $\alpha_{\mathrm{LP}}$ value (Table 1), where $\alpha_{\mathrm{LP}}=\operatorname{angle(LP-O-LP')/2}$. The maximal frequency for phenols $(\alpha=0)$ corresponds to the donor hydrogen atom located close to the $\mathrm{COH}$ plane which also contains the LPs which appear to have merged electron density lobes in experimental deformation maps (Fig. 4c). 
Alcohols display a different trend; the hydrogen atoms tend to be preferentially situated out of the $\mathrm{COH}$ plane. If the distance of $\mathrm{H}_{\mathrm{d}}$ to the $\mathrm{COH}$ plane is considered, the preferred value for alcohols is about $1.2 \AA$. The maximal frequency for $\mathrm{H}$-bonds with alcohol acceptors occurs in the range $\alpha=20$ $40^{\circ}$. This angle is however significantly smaller than the position of the LPs found in Table 1 which is at $\alpha_{\mathrm{LP}}=67^{\circ}$ (theoretical) and $\alpha_{\mathrm{LP}}=53^{\circ}$ (experimental). A smaller but significant part of the hydrogen bonding occurs for low $\alpha$ values, in the region between the two LPs.

The behaviour of C-O-C oxygen acceptors is also illustrated in Fig. 5. Ethers involving two $\mathrm{sp}^{2}$ carbon atoms and esters have two very close LPs, contrarily to $\mathrm{Csp}^{3}-\mathrm{O}-\mathrm{Csp}^{3}$ ethers (Fig. 3). This discrepancy is however not retrieved in the H-bond analysis, as the three types of C-O-C groups display similar $\alpha$ angle frequency diagrams. The most frequent $\mathrm{H}$-bonding to $\mathrm{C}-\mathrm{O}-\mathrm{C}$ acceptors occurs in all cases for low $\alpha$ angles, i.e. close to the C-O-C plane. The main discrepancy with phenols/alcohols is that $\mathrm{C}-\mathrm{O}-\mathrm{C}$ acceptors show a larger frequency of $\mathrm{H}$-bonds at high $\alpha$ angles in the $70-90^{\circ}$ range. This could be due to the fact that $\mathrm{C}-\mathrm{O}-\mathrm{C}$ oxygen atoms are weak hydrogen bond acceptors (ester and ethers are hydrophobic), displaying therefore lower directionality.

To compare the stereochemistry of weaker and stronger hydrogen bonds, cut-offs were applied for $\mathrm{O} \cdots \mathrm{H}_{\mathrm{d}}$ distances at $1.7 \AA$ and $2 \AA$. For alcohol acceptor $\mathrm{H}$-bonds with $\mathrm{O} \cdots \mathrm{H}_{\mathrm{d}}$ distances shorter than $2 \AA$, the histogram of $\alpha$ angles gives the highest frequencies between 10 and $40^{\circ}$ (Fig. 6a). For weaker H-bonds, the frequency is nearly constant for $\alpha$ angles in the range $\left[0^{\circ}, 60^{\circ}\right]$. Steiner $(2002)^{48}$ had observed that the directionality of moderate and weak hydrogen bonds is much softer, but can still be identified with the orientation of electron lone pairs. The occurrence of $\mathrm{H}-$ bonds decreases gradually at high $\alpha$ angle down to zero at $\alpha=90^{\circ}$, but the decrease is faster for the stronger H-bonds.

The $\beta$ parameter, defined as the angle between the LPs plane and the $\mathrm{O} \cdots \mathrm{H}_{\mathrm{d}}$ direction (Fig. 1 and 2), was also analyzed. The $\mathrm{H}$-bonds with short $\mathrm{O} \cdots \mathrm{H}_{\mathrm{d}}$ distances show a frequency histogram of $\beta$ angles 
which is more narrow, both for alcohols and phenols (Fig. 6b and 7b). For longer distance H-bonds, the $\beta$ frequency curve is broader, both for phenols and alcohols.

In the phenols case, the value of angle $\beta$ has a maximal frequency around zero; this is particularly the case for short H-bonds (Fig. 7b). For the H-bonds with distances $\mathrm{O} \cdots \mathrm{H}_{\mathrm{d}}$ larger than $2 \AA$, the $\beta$ frequencies are highest in the interval $\left[-25^{\circ},+20^{\circ}\right]$. The curves are dissymmetric with a larger number of $\mathrm{H}$-bonds taking negative $\beta$ values, which means that the donor atom $\mathrm{H}_{\mathrm{d}}$ is, on average, closer to $\mathrm{H}$ than to $\mathrm{C}$ in the $\mathrm{COH}$ group. Even for long distance $\mathrm{H}$-bonds, large positive $\beta$ values, with $\mathrm{H}_{\mathrm{d}}$ closer to the carbon atom, are very unfavourable in phenols.

Alcohols show a slightly different behaviour, the frequency $\beta$ curve is even more dissymmetric. The maximum of occurrences appear around $\beta=-8^{\circ}$, which is slightly out of the lone pairs plane, towards the hydrogen atom. This is the case especially for strong H-bonds. The frequency curve, more tilted towards the negative $\beta$ values, can be attributed to the steric hindrance of the bulky alkyl group which favours presence of the donor $\mathrm{H}_{\mathrm{d}}$ atom on the side of the alcohol hydrogen atom. When weak $\mathrm{H}-$ bonds are considered, the curve is more symmetrical with highest frequencies in the $\left[-20,+20^{\circ}\right]$ interval.

\subsection{Carbonyl acceptors.}

For carbonyl, the lone pairs plane is identical to the $\mathrm{XYC}=\mathrm{O}$ atoms plane and corresponds to a different geometry compared to $\mathrm{sp}^{3}$ oxygen atoms (Fig. 1 and 2). The oxygen atom with its unique double bond has two lone pairs which are more apart than in the different types of oxygen atoms with two simple covalent bonds, except the epoxy group. The LP-O-LP' angle found in both experimental and theoretical deformation electron density maps is larger than the $120^{\circ}$ of a trigonal geometry (Table 1, Fig. 3h).

The H-bond directionality greatly depends on the distance between the hydrogen and acceptor oxygen atoms. The $\alpha$ and $\beta$ angles distributions show that the directionality is actually very sharp for $\mathrm{H}$-bonds with short $\mathrm{O} \cdots \mathrm{H}_{\mathrm{d}}$ distance (Fig. 8a,b). Most of H-bonds with short $d\left(\mathrm{O} \cdots \mathrm{H}_{\mathrm{d}}\right)$ occur at $\alpha \approx 60 \pm 10^{\circ}$ and $\beta<15^{\circ}$, which corresponds to the donor $\mathrm{H}_{\mathrm{d}}$ atom located close to a trigonal geometry, as foreseen by 
Taylor \& Kennard (1984) ${ }^{9}$. For intermediate $d\left(\mathrm{O} \cdots \mathrm{H}_{\mathrm{d}}\right)$ distances, the H-bonds frequency histogram shows a maximum around $\alpha=56^{\circ}$ and the curve is more widespread. For distances larger than $2 \AA$, the frequency graph is quite flat with a large plateau for $\beta=5-70^{\circ}$.

One striking difference with the equivalent curves obtained for $\mathrm{sp}^{3}$ oxygen acceptors in alcohols and phenols (Figs. 6a, 7a), is the quasi zero frequency of $\mathrm{H}$-bonds occurring at low $\alpha$ angles, particularly for the short $\mathrm{O} \ldots \mathrm{H}_{\mathrm{d}}$ distances. The non favourable position of $\mathrm{H}$ atoms for $\mathrm{C}=\mathrm{O} \cdots \mathrm{H}$ angles close to $180^{\circ}$ was explained by Wiberg et al.(1994) ${ }^{51}$ from an energetic point of view; they however found that for $\mathrm{Li}^{+}$ions, on the contrary, $\mathrm{C}=\mathrm{O} \cdots \mathrm{Li}$ angles of $180^{\circ}$ are preferred.

It is observed that the preferred orientation of hydrogen bonds is always with the $\mathrm{H}_{\mathrm{d}}$ donor atom located close to the $\mathrm{XYC}=\mathrm{O}$ plane $(\beta=0)$, whether short or long $\mathrm{O} \cdots \mathrm{H}_{\mathrm{d}}$ distances are considered (Fig. $8 \mathrm{~b})$. The frequency distribution always decreases monotonously with the angle $\beta$ varying from 0 to $90^{\circ}$, whatever the range of $\mathrm{O} \cdots \mathrm{H}_{\mathrm{d}}$ distances considered. This trend is accentuated for short distance $(d<1.7 \AA)$ hydrogen bonds. The majority of $\mathrm{H}$-bonds tend to form with $\beta$ angles lower than $14^{\circ}$.

\subsection{Analysis as a function of H-bond length.}

To illustrate differently the trend of directionality as a function of H-bond length, the hydrogen bonds were sorted with increasing $\mathrm{O} \cdots \mathrm{H}_{\mathrm{d}}$ distances. The $\alpha$ and $\beta$ angles were then averaged over samples of 800,100 and 400 consecutive distances for alcohol, phenol and carbonyl, respectively (Fig. 9).

The mean $\alpha$ value tends to increase when the $\mathrm{O} \cdots \mathrm{H}_{\mathrm{d}}$ distances become longer for both phenol and alcohol groups. The $\langle\alpha\rangle$ angle (Fig. 9a) takes generally values between 1 and $10^{\circ}$ smaller for phenols than for alcohols; for very strong hydrogen bonds, the values are respectively $22^{\circ}$ and $26^{\circ}$.

For carbonyl, the average value $\langle\alpha\rangle$ has a different behaviour and is generally much larger, compared to phenols/alcohols. The average value of carbonyl $\alpha$ angle tends generally to 
decrease from short to medium distance and increases again at long $\mathrm{O} \cdots \mathrm{H}_{\mathrm{d}}$ distance. For short distance hydrogen bonds, the $\langle\alpha\rangle$ value is about $56 \pm 8^{\circ}$ which corresponds to the angles of highest frequency in Fig. 8a and originates from the positions of the well separated carbonyl electron LPs . For medium and long distance carbonyl hydrogen bonds, the mean $\alpha$ angle is around 40 and $45^{\circ}$, respectively.

The rmsd of $\alpha$ angles shows similar trends and values for the three types of acceptors. The $\operatorname{rmsd}(\alpha)$ value within the samples is gradually increasing with the H-bond distance from 10 to $25^{\circ}$, which illustrates the higher directionality of short distance H-bonds for the three acceptor types.

In order to compare $\beta$ angles of phenol/alcohol and of carbonyl, which are respectively nonsymmetric and symmetric with respect to electron lone pairs plane, the absolute value of $\beta$ was considered. The average value of $|\beta|$ is progressively increasing with the $\mathrm{O} \ldots \mathrm{H}_{\mathrm{d}}$ distance for the three chemical groups (Fig. 9b).

The H-bonds occur, on average, in directions more out of the LPs plane for carbonyl than for alcohols/phenols as illustrated by the larger average $|\beta|$ values. This could be explained by the lack of steric hindrance around the carbonyl oxygen on both sides of the electron lone pairs plane which coincides with the $>\mathrm{C}=\mathrm{O}$ atoms $\mathrm{sp}^{2}$ plane.

The $|\beta|$ values are quite small for short hydrogen bonds with alcohol and phenol acceptors $\left(<|\beta|>=6 \pm 6^{\circ}\right)$. The average $|\beta|$ value is also generally smaller by a few degrees for phenols compared to alcohols, except for weak H-bonds. This indicates that hydrogen bonding on phenol acceptors has the propensity to occurs, on average, closer to the LPs plane compared to alcohols. When the sign of angle $\beta$ is considered for alcohols and phenols, there are more H-bonds with negative $\beta$ values, indicating that the $\mathrm{H}_{\mathrm{d}}$ donor positioning is favoured on the $\mathrm{H}$ side of the $\mathrm{C}-\mathrm{O}$ $\mathrm{H}$ bisecting plane, presumably due to lower steric hindrance. 
For strong hydrogen bonds involving carbonyl acceptors, the average value of $|\beta|=9 \pm 9^{\circ}$ is slightly

larger than for phenol/alcohol. For medium and low strength hydrogen bonds, the $\langle|\beta|>$ value increases gradually in the $20^{\circ}$ to $26^{\circ}$ range with distance. Long distance H-bonds, at the limit of van der Waals interactions, still show significant directionality with average $|\beta|$ angles limited to $26 \pm 22^{\circ}$ and H-bonds with O...Hd perpendicular to the LPs plane are scarce (Fig. 8b).

The $|\beta|$ rmsd values are generally increasing with the distance for all three acceptor types. The rmsd of $|\beta|$, like the average value, is considerably larger for carbonyl compared to alcohol/phenol.

When the two average angles are compared, the value of $<\alpha>$ is always larger than that of $<|\beta|>$ for the three types of acceptors. Even at long distance, the difference is still larger than $20^{\circ}$ (Fig. 9a,b). For alcohols and phenols, large $|\beta|$ values are particularly disfavoured, presumably by stereochemical hindrance of the hydrogen donor $\mathrm{H}_{\mathrm{d}}$ with the $\mathrm{C}$ and $\mathrm{H}$ atoms of the $\mathrm{COH}$ group. For carbonyl, there is no such hindrance. The larger $\langle\alpha\rangle$ values compared to $\langle\beta\rangle$ for weak carbonyl H-bonds suggest that, at the limit of van der Waals contacts, the LPs have still some significant influence on the directionality of the polar $>\mathrm{C}=\mathrm{O} \cdots \mathrm{H}_{\mathrm{d}}$ interactions.

A comparison of the $\mathrm{O} \ldots \mathrm{H}_{\mathrm{d}}$ intermolecular distances between $\mathrm{HN}$ and $\mathrm{HO}$ donors is presented in the Fig. 10. In all three cases, the $\mathrm{O} \cdots \mathrm{H}_{\mathrm{d}}$ distance is, on average, shorter for $\mathrm{OH}$ donors compared to $\mathrm{NH}$ donors. The difference in the $\mathrm{O} \cdots \mathrm{H}_{\mathrm{d}}$ distance between the $\mathrm{HO}$ and $\mathrm{HN}$ groups is linked to the greater electropositivity of $\mathrm{HO}$ hydrogen atoms compared to $\mathrm{HN}$ donors. In the case of alcohols, the maximal frequency lies around $d\left(\mathrm{O} \cdots \mathrm{H}_{\mathrm{d}}\right)=1.78 \AA$ for $\mathrm{OH}$ donors whereas for $\mathrm{NH}$ donors the maximum is observed for a longer distance situated around $1.93 \AA$.

For phenols, the maxima for $\mathrm{OH}$ and $\mathrm{NH}$ donors at $d=1.82 \AA$ and $d=2.02 \AA$, respectively, appear at slightly higher H-bond distances than in alcohols, especially for $\mathrm{HN}$ donors. The carbonyl 
acceptors show a similar trend with $\mathrm{O} \cdots \mathrm{H}_{\mathrm{d}}$ distances globally shorter for $\mathrm{HO}$ donors than for $\mathrm{HN}$, the preferred distances being around $1.80 \AA$ and $1.90 \AA$, respectively. Steiner (2002) ${ }^{48}$ found this result for several acceptor types and deduced that the $\mathrm{HO}$ donors can be ranked as stronger than $\mathrm{HN}$ donors.

Among the three types of oxygen acceptors, phenols show the highest percentage of H-bonds occurring at longer $\mathrm{O} \cdots \mathrm{H}_{\mathrm{d}}$ distance, both for $\mathrm{HO}$ and $\mathrm{HN}$ donors. There are significant differences in the hydrogen bonding patterns between carbonyl and the two $\mathrm{OH}$ acceptors. Carbonyl acceptors show the highest percentage of very short hydrogen bonds. This is due to the larger negative charge carried by the carbonyl oxygen atom compared to the two $\mathrm{OH}$ groups. Carbonyl is the only one among the three acceptors represented in Fig. 10. to display very strong hydrogen bonds with $\mathrm{O} \ldots \mathrm{H}_{\mathrm{d}}$ distances shorter than $1.6 \AA$ and these involve essentially $\mathrm{HO}$ donors. The vast majority of $\mathrm{H}$-bonds with $d\left(\mathrm{O} \ldots \mathrm{H}_{\mathrm{d}}\right)<1.65 \AA$ occur in $\mathrm{O} \cdots \mathrm{H}-\mathrm{O}$ interactions with a carbonyl acceptor and secondarily with alcohols.

\subsection{Uncertainty on the $H$ atom localization.}

Steiner and Saenger ${ }^{52}$ observed a general lengthening of the covalent O-H bond in O-H...O hydrogen bonds as the $\mathrm{O} \cdots \mathrm{H}$ or $\mathrm{O} \cdots \mathrm{O}$ distance becomes shorter in a set of organic compounds structures determined at low temperature by neutron diffraction. If a small minority of very strong H-bonds are ignored, the $\mathrm{O}-\mathrm{H}$ bond length is generally only altered within $\pm 0.04 \AA$ from the average distance. This variability of the $\mathrm{O}-\mathrm{H}$ bond lengths only affects to a small extend the $\alpha$ and $\beta$ angles values (Fig. 1) analysed in this study. In the most severe cases, the error on the angles due to this effect can reach $1.5^{\circ}$.

The database analysis includes cryogenic and room temperature data sets. The hydrogen parameters such as donor-hydrogen and hydrogen $\cdots$ acceptor distances show also some dependence on the temperature at which the diffraction experiment is carried out. For instance, in a neutron diffraction study at several temperatures, it was found that the O-H and N-H bond lengths in paracetamol decrease (-0.025 and $-0.028 \AA$, respectively) when the temperature varies from 20 to $330 \mathrm{~K}^{53}$. On the other hand, the corresponding $\mathrm{O} \cdots \mathrm{H}$ distances showed an increase of $0.035(+2 \%)$ and $0.067 \AA(+3.5 \%)$ upon this temperature variation. Therefore, the bias introduced by temperature on the analyzed angles can generally be expected to be lower than $2^{\circ}$. 
In extremely short hydrogen bonds, the distance variations can be much larger when temperature-dependent proton migration occurs. This is the case for pyridine-3,5-dicarboxylic acid where the $\mathrm{N}-\mathrm{H}$ and $\mathrm{H} \cdots \mathrm{O}$ distance values are 1.213 (4) and 1.311 (5) $\mathrm{A}^{\circ}$ at $15 \mathrm{~K}$ and change to 1.308 (6) and 1.218 (6) $\AA$ at $300 \mathrm{~K}^{49}$. Nevertheless, in such strong H-bonds, the D$\mathrm{H} \cdots \mathrm{A}$ atoms are generally close to alignment ${ }^{52}$ and therefore the influence of the proton shift on the $\alpha$ and $\beta$ angles is small.

The fact that some hydrogen atoms are not located in the electron density but placed automatically by the crystallographic software does introduce some error in the data analyzed in stereochemical studies based on the CSD. This applies for chemical group with a rotational degree of freedom like hydroxyl, phenol and $-\mathrm{NH}^{3+}$, but generally not to $\mathrm{N}-\mathrm{H}$ donors. The analysis of the local environment of the hydrogen atom and the presence of a hydrogen acceptor, which is the case here, can however guide the crystallographer to place the hydrogen atom close to its real position.

\section{Conclusion}

The stereochemistry of hydrogen bonding was studied in the light of the charge density of the oxygen atom for alcohols, phenols and carbonyl groups. The charge density analysis reveals that different oxygen atoms have remarkable fine differences in their electron density and LPs localization. On the basis of these differences, the hydrogen bonding pattern of the different oxygen atom types were investigated by an extensive survey of the CSD database of crystallographic structures. The observed geometries for hydrogen bonding found in the CSD database are the resultant of the hydrogen bonding attractions and of the other crystal forces.

The small to significant differences of electron density in different oxygen atom acceptors were verified to have a statistical influence on the hydrogen bonding geometry. The hydrogen bonding pattern of oxygen acceptors is particularly related to the configuration of the electron lone pairs. A fine discrepancy is observed in two types of $\mathrm{COH}$ groups, alcohols and phenols. The LPs charge density shows small to significant differences between experiment and theory.

It might be worth testing some other basis sets and check if a better agreement can be achieved for oxygen acceptors like phenols. The merging of lone pairs lobes for phenols observed in experimental electron densities could alternatively be attributed to weak high resolution diffraction data. In addition, atomic thermal motion is also known to be responsible for attenuation of the deformation electron density features. Deformation peaks on LPs sites are 
generally stronger and sharper in theoretical maps compared to experimental ones as observed also in Fig. $3 \mathrm{~b}\left(\Delta \rho_{\max }=0.8 \mathrm{e} / \AA^{3}\right)$ and Fig. $4 \mathrm{c}\left(\Delta \rho_{\max }=0.6 \mathrm{e} / \AA^{3}\right)$.

This directionality influence is strongest for short distance $\mathrm{O} \cdots \mathrm{H}_{\mathrm{d}}$ interactions; it is diminished but does not completely vanish for longer distances. For strong H-bonds, the hydrogen atom tends to be close to the electron LPs plane $\left(|\beta|<10^{\circ}\right)$. For weaker interactions the $\mathrm{O} \ldots \mathrm{H}_{\mathrm{d}}$ direction is still generally close within $|\beta|<30^{\circ}$ to that plane. For phenols and alcohols, the donor hydrogen atoms are, on average, closer to the LPs plane than for carbonyl.

The knowledge about the fine patterns of hydrogen bonding with oxygen acceptors can have potential significance for supra-molecular crystal engineering. The stereochemistry of hydrogen bonds in small molecules resembles that of protein-ligand environment as verified by Klebe (1994) ${ }^{55}$. Therefore, results of stereochemical studies of hydrogen bonds in the CSD can also be applied for rational protein drug design.

Acknowledgements: MA thanks the Higher Education Commission of Pakistan (HEC) for financial assistance. 


\section{References:}

(1) Nobeli, I.; Price S.L.; Lommerse, J.P.M.; Taylor, R. J. Comput. Chem. 1997, 38, 2060-2074.

(2) Desiraju, G. R; Vittal, J. J.; Ramanan, A.; 2011. Crystal Engineering: A Textbook; Singapore: World Scientific Publishing Company.

(3) Mills, J. E. J.; Dean, P. J. Comp. Molec. Design, 1996, 10, 607-622.

(4) Galek, P.T.A.; Fábián, L.; Motherwell, W. D. S.; Allen, F. H.; Feeder. N. Acta Crystallogr. 2007. B63, 768-782.

(5) Kroon, J.; Kanters, J. A.; Van Duijneveldt-Van de Rijdt, J. G. C. M.; Van Duijjneveldt, F. B.; Vleigenthart, J. A. J. Mol. Struct. 1975, 24, 109-129.

(6) Ceccarelli, C.; Jeffrey, G. A.; Taylor, R. J. Mol. Struct. 1981, 70, 255-271.

(7) Olovsson, I. Croat. Chem. Acta. 1982, 55, 171-190.

(8) Taylor, R.; Kennard, O.; Versichel, W. J. Am. Chem. Soc. 1983, 105, 5761-5766.

(9) Taylor, R.; Kennard, O. Acc. Chem. Res. 1984, 17, 320-326.

(10) Taylor, R.; Kennard, O.; Versichel, W. Acta. Crystallogr. 1984, B40, 280-288.

(11) Dutta, S.; Zardecki, C.; Goodsell, D. S.; Berman, H. M. J. Appl. Cryst. 2010, 43, 12241229.

(12) Allen, F. H. Acta Crystallogr. 2002, B58, 380-388.

(13) Bruno, I. J.; Cole, J. C.; Edgington, P. R ; Kessler, M ; Macrae, C. F.; McCabe, P; Pearson, J. R.; Taylor, R. Acta Crystallogr. 2002, B58, 389-397.

(14) Cambridge Structural Database System Users Manual, Vista 2.0 Users Guide, Cambridge Crystallographic Data Centre, 12 Union Road ,Cambridge ,UK, 1995.

(15) Macrae, C. F.; Bruno, I. J.; Chisholm, J. A.; Edgington, P. R.; McCabe, P.; ; Pidcock, E.; Rodriguez-Monge, L.; Taylor, R.; van de Streek, J.; Wood, P. A. J. Appl. Crystallogr. 2008, 41, 466-470.

(16) Wood, P. A.; Pidcock, E.; Allen, F. H. Acta Crystallogr. 2008, B64, 491-496.

(17) Murray-Rust, P.; Glusker, J. P. Am. Chem. Soc. 1984, 106, 1018-1025.

(18) Hay, B. P.; Dixon, D. A.; Jeffrey, C. B.; Moyer, B. A. J. Am. Chem. Soc. 2002, 124, 182183.

(19) Wood, P. A.; Allen, F. H.; Pidcock, E. CrystEngComm. 2009, 11, 1563-1571. 
(20) Coppens, P. X-ray Charge Densities and Chemical Bonding, 1997. New York: Oxford University Press.

(21) Coppens, P. Acta Cryst. 1998. A54, 779-788.

(22) Tsirelson, V. G.; Ozerov, R. P. Electron Density and Bonding in crystals, Bristol: 1996. Institute of Physics Publishing.

(23) Jelsch, C.; Teeter, M. M.; Lamzin, V.; Pichon-Pesme, V.; Blessing, R. H.; Lecomte, C. Proc. Natl. Acad. Sci. (USA) 2000, 97, 3171-3176.

(24) Spackman, M. A. Annu. Rep. Prog. Chem. Sect. C: Phys. Chem. 1997, 94. 177-207.

(25) Koritsanszky, T. S.; Coppens, P. Chem. Rev. 2001, 101. 1583-1621.

(26) Munshi, P.; Guru Row, T. N. Cryst. Eng. Comm. 2005, 7, 608-611.

(27) Lecomte, C.; Aubert, E.; Legrand, V.; Porcher, F.; Pillet, S.; Guillot, B.; Jelsch, C. Zeitschrift Kristallogr. 2005, 220.4, 373-384.

(28) Hohenberg, P.; Kohn, W. Phys. Rev. B, 1964, 136, 864-871.

(29) Zarychta, B.; Pichon-Pesme, V.; Guillot, B.; Lecomte, C.; Jelsch, C. Acta Crystallogr. 2007, A63, 108-125.

(30) Domagala, S.; Munshi, P. M.; Ahmed, M.; Guillot, B.; Jelsch, C. Acta. Crystallogr. 2011, B67, 63-78.

(31) Bouhmaida, N.; Bonhomme, F.; Guillot, B.; Jelsch, C.; Ghermani. N. E. Acta Crystallogr. 2009. B65, 363-374

(32) Hansen, N, K.; Coppens, P. Acta. Crystallogr. 1978, A34, 909-921.

(33) Jelsch, C.; Guillot, B.; Lagoutte, A.; Lecomte, C. 2005. J. Appl. Crystallogr. 38, 38-54.

(34) Domagala, S.; Jelsch, C. J. Applied Crystallogr. 2008, 41, 1140-1149.

(35) Dovesi, R.; Saunders, V. R.; Roetti, C.; Orlandol, R.; Zicovich-Wilson, C. M.; Pascale, F.; Civalleri, B.; Doll, K.; Harrison, N. M.; Bush, I. J.; D'Arco, Ph.; Llunell, M. 2008, CRYSTALO6 1.0. Version 1_0_2. University of Turin, Italy.

(36) Hübschle, C. B.; Dittrich, B.; Grabowsky, S.; Messerschmidt, M.; Luger, P. Acta Crystallogr. 2008. B64, 363-374.

(37) Munshi, P.; Jelsch, C.; Hathwar, V. R.; Guru Row, T. N. Cryst. Growth Des. 2010, 10, 1516-1526.

(38) Vojinović, K.; Losehand, U.; Mitzel, N.W. Dalton Trans. 2004, 2578 - 2581. 
(39) Bakir, M.; Facey, P. C.; Hassan, I.; Mulder, W. H.; Porter, R. B. Acta Crystallogr. 2004. C60, o798-0800.

(40) Grabowsky, S.; Weber, M.; Buschmann, J.; Luger, P. Acta Crystallogr. 2008. B64, 397400.

(41) Lee, C.; Yang, W.; Parr, R. G. Phys. Rev. 1988, B37, 785-789.

(42) Becke, A. D. J. Chem. Phys. 1993, 98, 5648-5652.

(43) Hariharan, P. C.; Pople, J. A. Theor. Chim. Acta, 1973, 28, 213-222.

(44) Le Page, Y.; Gabe, E. J. J. Appl. Crystallogr. 1979, 12, 464-466.

(45) Allen, F. H.; Bruno, I. J. Acta Crystallogr. 2010. B66, 380-386.

(46) Koch, U.; Popelier, P. L. A. J. Phys. Chem., Am. Chem. Soc., 1995, 99, 9747-9754.

(47) Arunan, E.; Desiraju, R. G.; Klein, R. A.; Sadlej J.; Scheiner, S.; Alkorta I.; Clary, D.C.; Crabtree R.H.; Dannenberg J. J.; Hobza, P.; Kjaergaard, H. G.; Legon, A.C.; Mennucci, B. Nesbitt, D. J. Pure Appl. Chem. 2011, 83, 1619-1636.

(48) Steiner, T. Angew. Chem. Int. Ed. 2002, 41, 48-76.

(49) Bondi, A. J. Phys. Chem. 1994, 68, 441-451.

(50) Rowland, R. S.; Taylor, R. J. Phys. Chem, 1996, 100, 7384-7391.

(51) Wiberg, K. B.; Marquez, M.; Castejon, H. J. Org. Chem. 1994, 59, 6817-6822.

(52) Steiner T.; Saenger, W. Acta Crystallogr. 1994, B50, 348-357.

(53) Wilson C.C. Zeitschrift Kristallogr. 2000. 215, 693-701.

(54) Cowan, J. A.; Howard, J. A. K.; McIntyre, G. J.; Loc S. M.-F; Williams, I.D. Acta Crystallogr. 2005. B61, 724-730.

(55) Klebe, G. J. Mol Biol. 1994, 237, 212-235. 


\section{Table 1}

LP-O-LP' angles found for the different oxygen atom types in the electron density maps derived from the theoretical calculations / experiment. The lone pairs are positioned on the peaks maxima in the deformation electron density maps (Fig. 3, 4). The reference of the molecular crystal structure used for the theoretical/experimental maps calculation is given. M means that the two lobes appear merged with a unique maximum. The resolution refers to the diffraction data of the experimental charge density.

\begin{tabular}{|c|c|c|c|c|}
\hline $\begin{array}{l}\text { chemical } \\
\text { type }\end{array}$ & Angle $\left(^{\circ}\right)$ & $\begin{array}{l}\text { Molecule theo/ } \\
\text { exp }\end{array}$ & $\begin{array}{l}\text { Resolution }(\AA) \\
\text { Temperature Completeness }\end{array}$ & Reference \\
\hline alcohol & $135 / 106$ & thymidine & $0.55 \quad 20 \mathrm{~K} \quad 91.2 \%$ & 36 \\
\hline water & 132 / n.d. & quercetin $\mathrm{HOH}$ & n.d. & 30 \\
\hline phenol & $104 / \mathrm{M}$ & $\begin{array}{l}\text { quercetin } \mathrm{HOH} / \\
\text { paracetamol }\end{array}$ & $0.41 \quad 100 \mathrm{~K} \quad 84.2 \%$ & $\begin{array}{l}30 \\
/ 31\end{array}$ \\
\hline ether $\left(\mathrm{Csp}^{3}\right)$ & $134 / 125$ & thymidine & $0.55 \quad 20 \mathrm{~K} \quad 91.2 \%$ & 36 \\
\hline $\begin{array}{l}\text { ether in } \\
\text { cycle }\end{array}$ & M / n.d. & quercetin $\mathrm{HOH}$ & n.d. & 30 \\
\hline ester & $82 / \mathrm{M}$ & coumarin 314 & $0.46100 \mathrm{~K} \quad 98.8 \%$ & 37 \\
\hline ester in cycle & $\mathrm{M} / \mathrm{M}$ & $\begin{array}{l}\text { dimethyl ether / } \\
\text { coumarin } 314\end{array}$ & $0.46100 \mathrm{~K} \quad 98.8 \%$ & $\begin{array}{l}38 \\
137\end{array}$ \\
\hline carbonyl & $151 / 144$ & thymidine & $0.55 \quad 20 \mathrm{~K} \quad 91.2 \%$ & 30 \\
\hline epoxide & $154 / 160$ & $\begin{array}{l}\text { mikanolide / } \\
\text { ethylene oxide }\end{array}$ & $0.50100 \mathrm{~K} \quad 100 \%$ & $\begin{array}{l}39 \\
/ 40\end{array}$ \\
\hline
\end{tabular}


Figure 1. Geometry defining the angles $\alpha$ and $\beta$ for the $\mathrm{sp}^{2}$ oxygen atoms (carbonyl $\mathrm{C}=\mathrm{O}$ ). Due to the two local mirror symmetries of the carbonyl oxygen atom, both angles $\alpha$ and $\beta$ take only positive values. $\mathrm{P}$ is the projection of $\mathrm{Hd}$ on the $\mathrm{XYC}=\mathrm{O}$ plane containing the two lone pairs. $\mathrm{Q}$ is the projection of $\mathrm{Hd}$ on the $\mathrm{C}=\mathrm{O}$

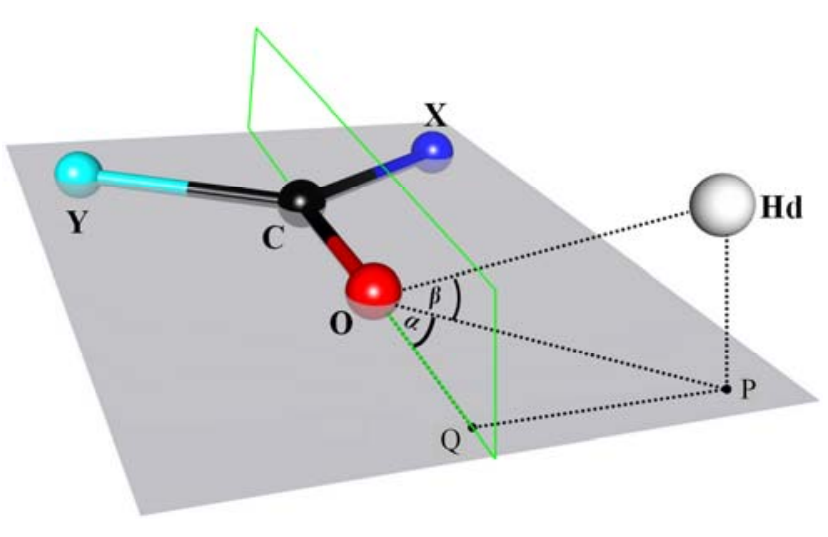
line.

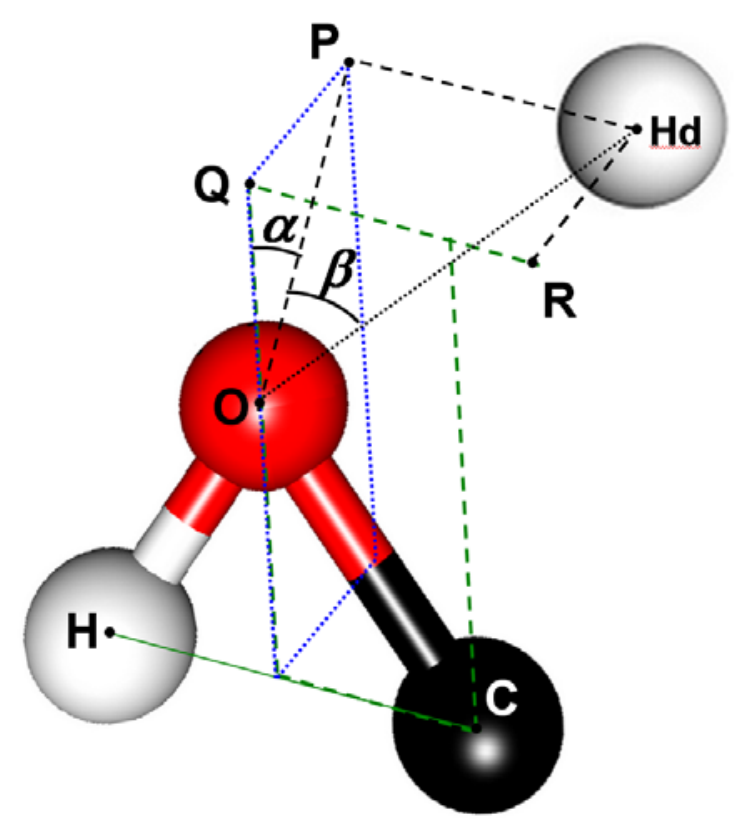

Figure 2. Geometry defining the angles $\alpha$ and $\beta$ for the $\mathrm{sp}^{3}$ oxygen atoms (C-O-H or more generally $\mathrm{X}-\mathrm{O}-\mathrm{Y}$ ). $\mathrm{R}$ is the projection of $\mathrm{Hd}$ on the $\mathrm{COH}$ plane and $\mathrm{P}$ on the plane formed by the oxygen atom and its two electron lone pairs, i.e. bisecting $\mathrm{COH}$. Q is the projection of $\mathrm{Hd}$ on the inner bisecting line of $\mathrm{COH}$.

The $\mathrm{COH}$ group follows only one symmetry (formed by the $\mathrm{COH}$ mirror plane), therefore, the $\alpha$ angle are defined with positive values. The hydroxyl oxygen atom is dissymmetric with respect to the $\mathrm{C}-\mathrm{O}-\mathrm{H}$ bisecting plane which allows negative or positive values for the $\beta$ angle, corresponding to $\mathrm{Hd}$ being on the side of $\mathrm{C}$ and $\mathrm{H}$, respectively. 


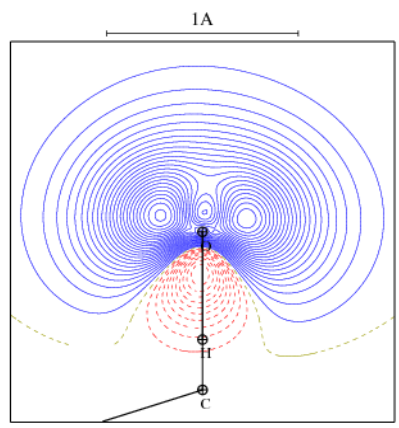

(a) Alcohol

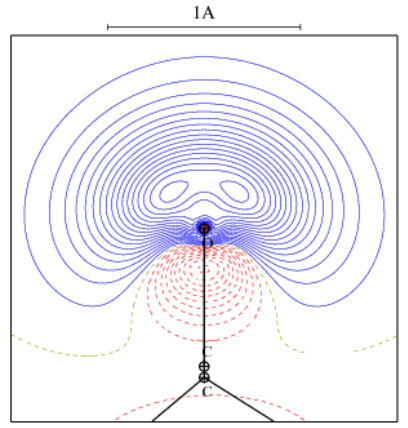

(c) Ester $\mathrm{C}\left(\mathrm{sp}^{3}\right)$

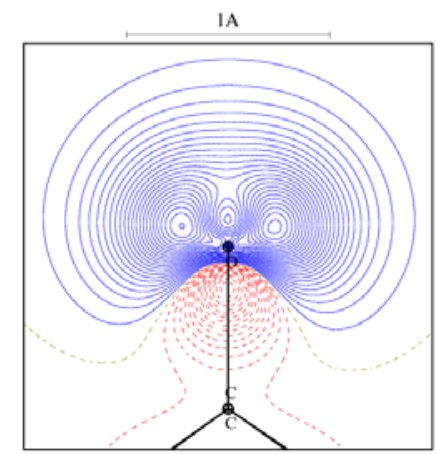

(e) Ether $\mathrm{C}\left(\mathrm{sp}^{3}\right)-\mathrm{O}-\mathrm{C}\left(\mathrm{sp}^{3}\right)$

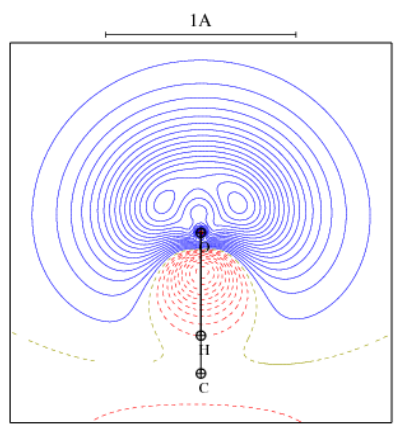

(b) Phenol

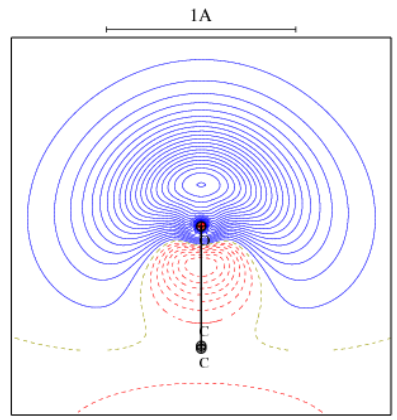

(d) Ester in aromatic cycle

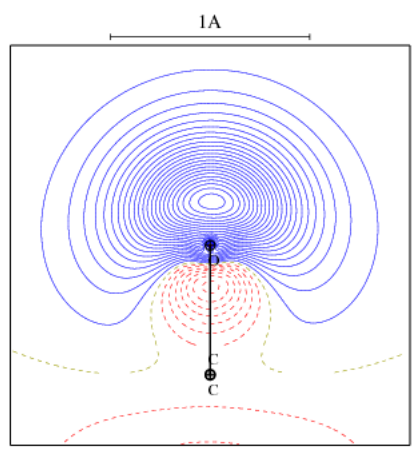

(f) Ether in aromatic cycle
Figure 3.

Maps of electron density deformation in the lone pairs plane as refined vs. the theoretical structure factors. Contours $\quad \pm 0.05 \mathrm{e} / \AA 3$. positive: solid blue lines. Negative: dashed red lines.

The molecules studied are indicated in Table 1. 


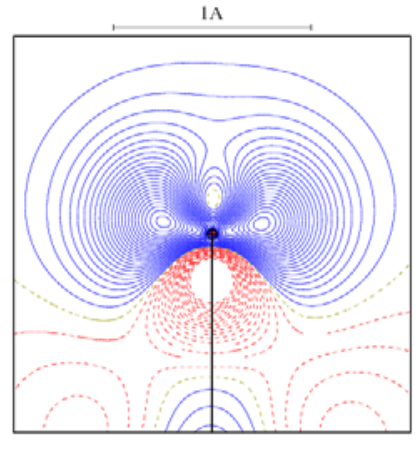

(g) epoxide

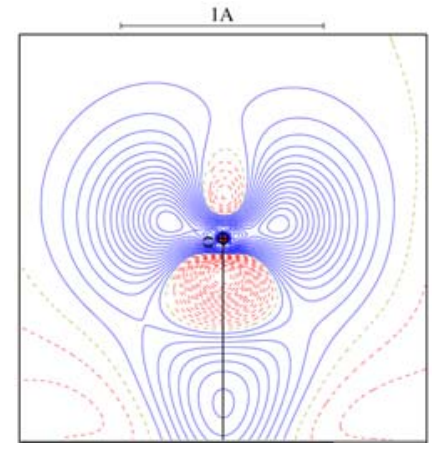

(h) Carbonyl 
Figure 4.

Maps of experimental deformation electron density for:

- the two ester oxygen atoms in coumarin 314, orange a)

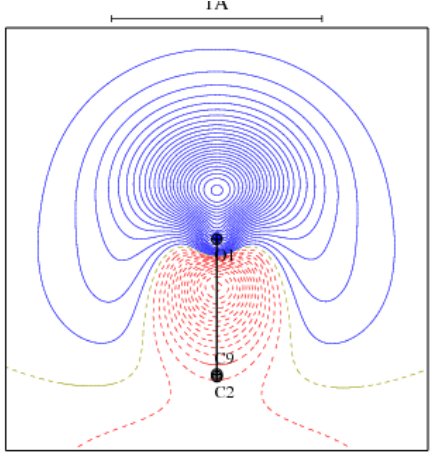
form (Munshi et al., 2010): (a) within the aromatic cycle, (b) within the $\mathrm{C}\left(\mathrm{sp}^{3}\right)$ ester side chain.

(c) the phenol group in paracetamol $^{31}$

b)

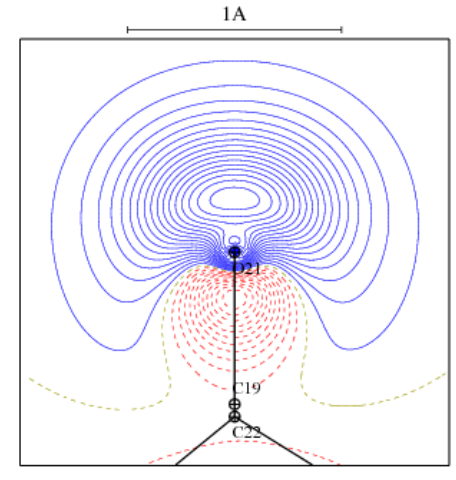

The views are shown in the plane bisecting the $\mathrm{C}-\mathrm{O}-\mathrm{C}$ or $\mathrm{C}-\mathrm{O}-\mathrm{H}$ group. Contours are as in Fig. 3.

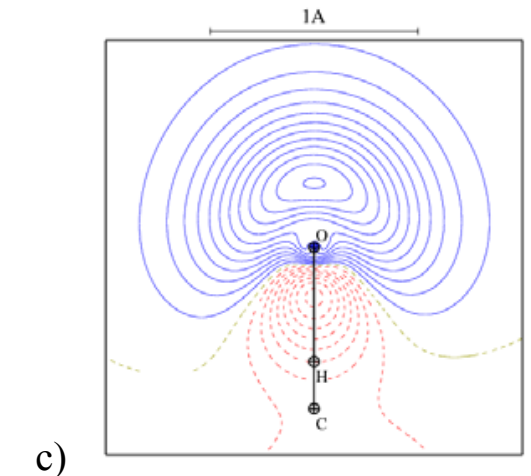




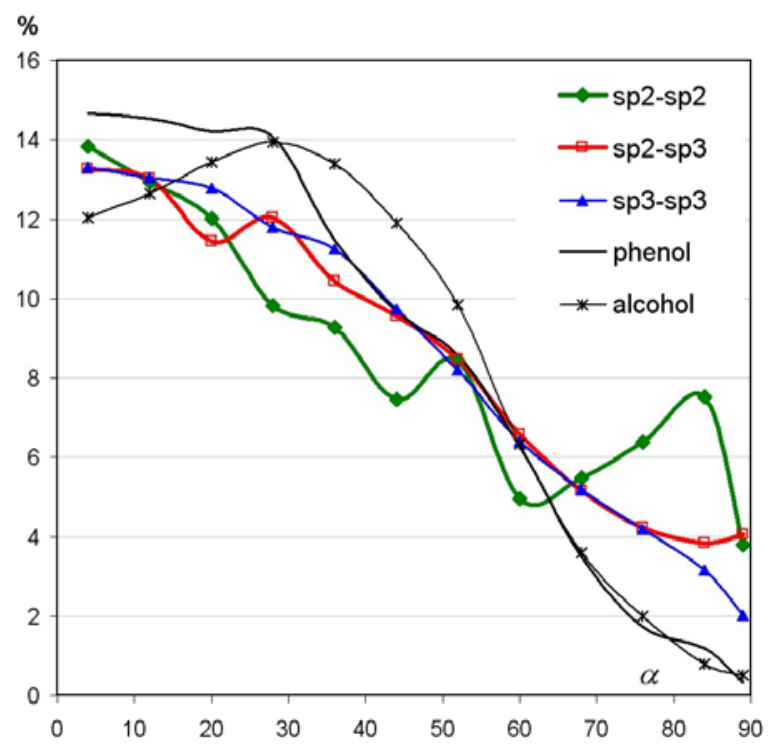

\section{Figure 5.}

Frequency of $\alpha$ angles $\left(^{\circ}\right)$ for hydrogen bonds in alcohols, phenols and $\mathrm{C}-\mathrm{O}-\mathrm{C}$ oxygen acceptors (ethers, esters). The C-O-C groups were differentiated depending on the hybridization of the two carbon atoms. $\quad \mathrm{C}\left(\mathrm{sp}^{2}\right)-\mathrm{O}-\mathrm{C}\left(\mathrm{sp}^{3}\right)$ groups include esters. 


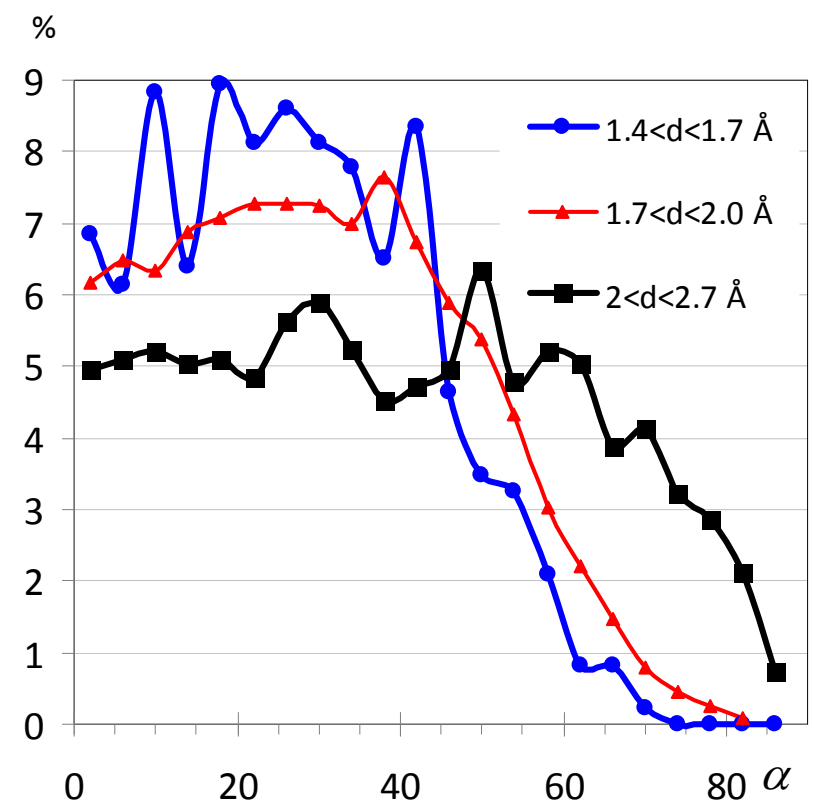

Figure 6

Frequency of angles $\left({ }^{\circ}\right)$ in all, short $d<2 \AA$ and long $d>2 \AA$ H-bonds with alcohol as acceptor. $d=d\left(\mathrm{O} \ldots \mathrm{H}_{\mathrm{d}}\right)$

(a) $\alpha$ angles,

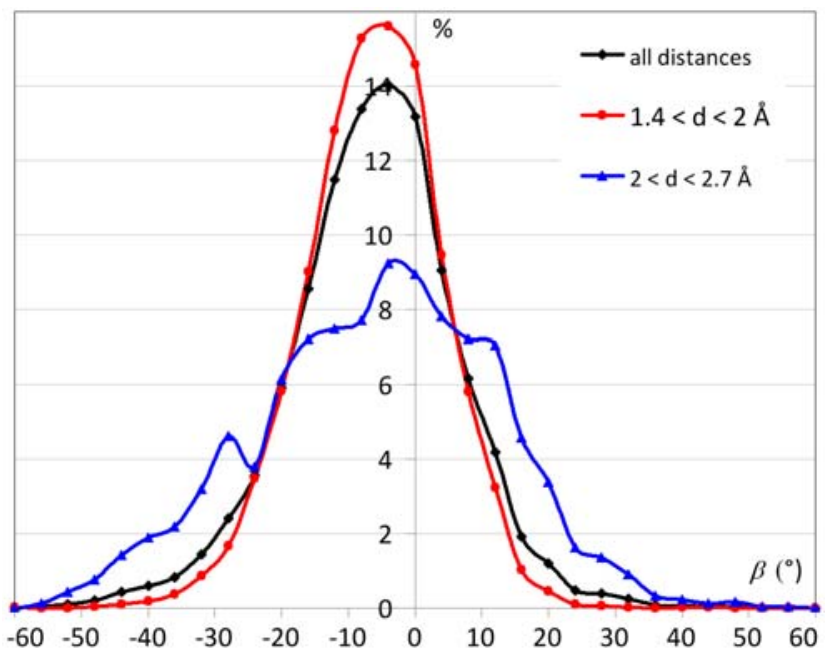

(b) $\beta$ angles $\left(^{\circ}\right)$ 


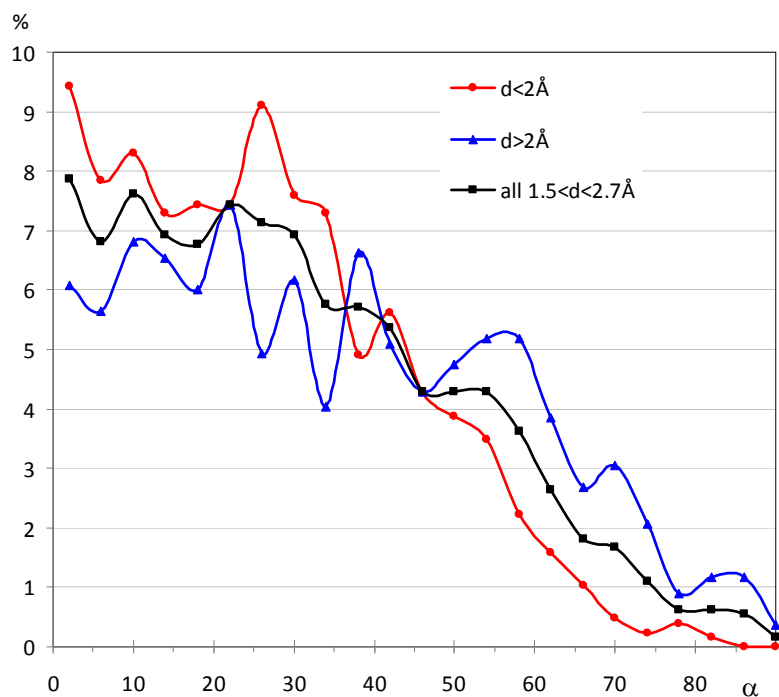

\section{Figure 7.}

Frequency of $\alpha$ angles $\left(^{\circ}\right)$ in all, long and short H-bonds with phenol as acceptor.

$d=d\left(\mathrm{O} \ldots \mathrm{H}_{\mathrm{d}}\right)$

(a) $\alpha$ angles $\left({ }^{\circ}\right)$

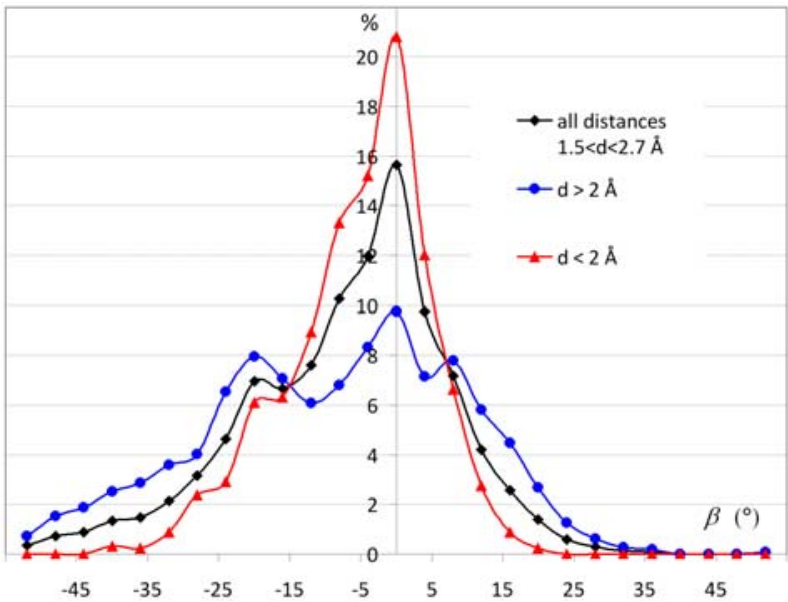

(b) $\beta$ angles $\left(^{\circ}\right)$ 


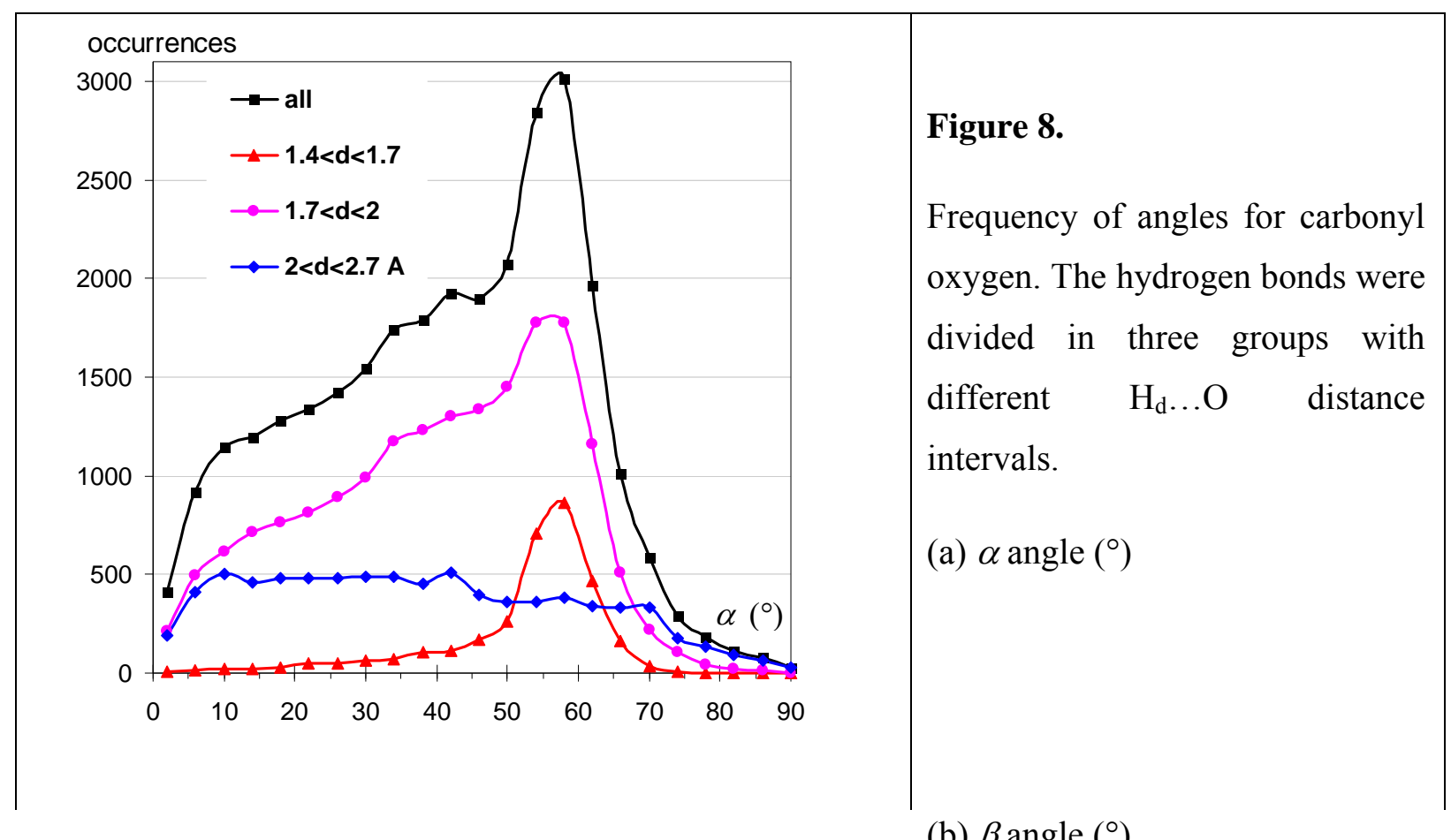

(b) $\beta$ angle ( ${ }^{\circ}$ )

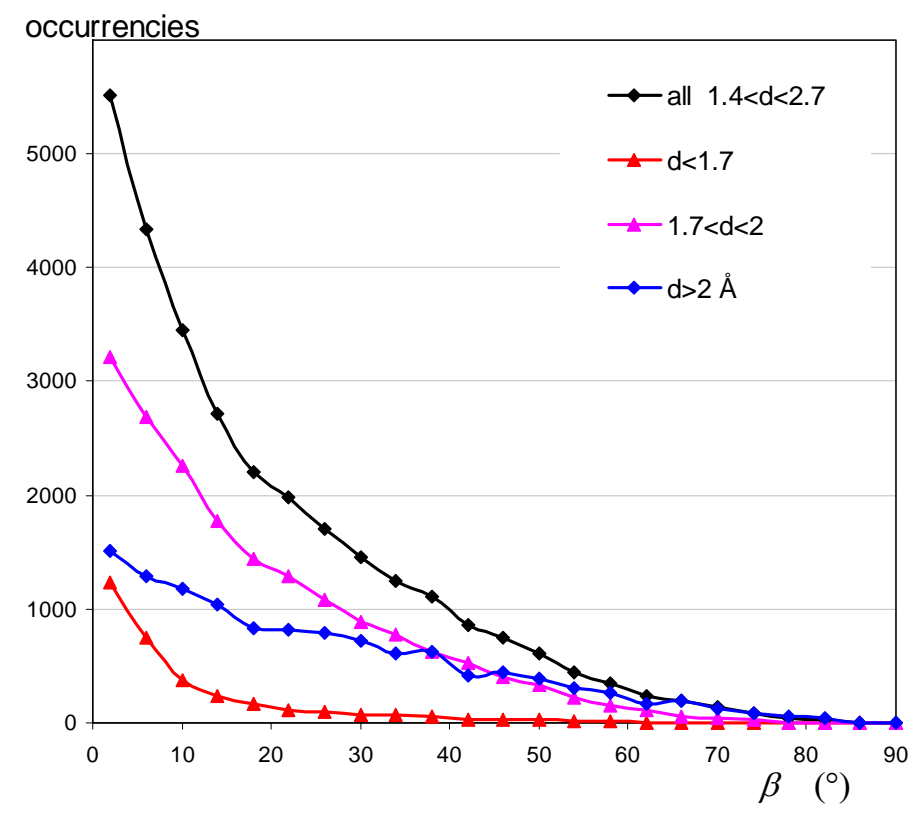



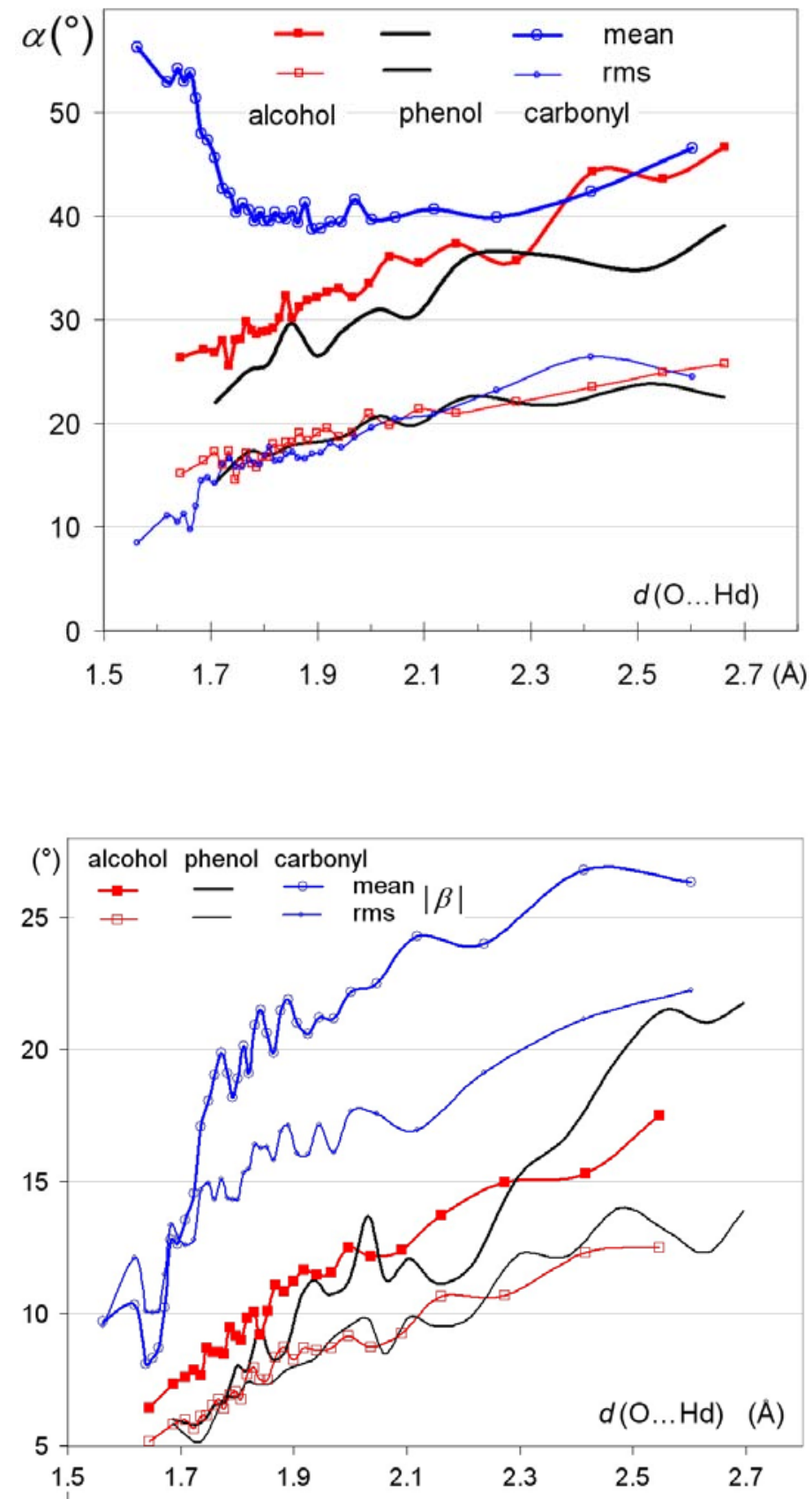

Figure 9

Average and rms value of $\alpha$ and $\beta$ angles as a function of $\mathrm{O} \ldots \mathrm{H}_{\mathrm{d}}$ distance in hydrogen bonds. The $\mathrm{H}-$ bonds were at first sorted according to increasing distances. The average and rmsd angles were then computed over samples of $800, \quad 100$ and 400 consecutive H-bonds for alcohol, phenol and carbonyl, respectively.
a) $<\alpha>$ and $\operatorname{rmsd}(\alpha)$
b) $<|\beta|>$ and $\operatorname{rmsd}(<|\beta|>)$ 


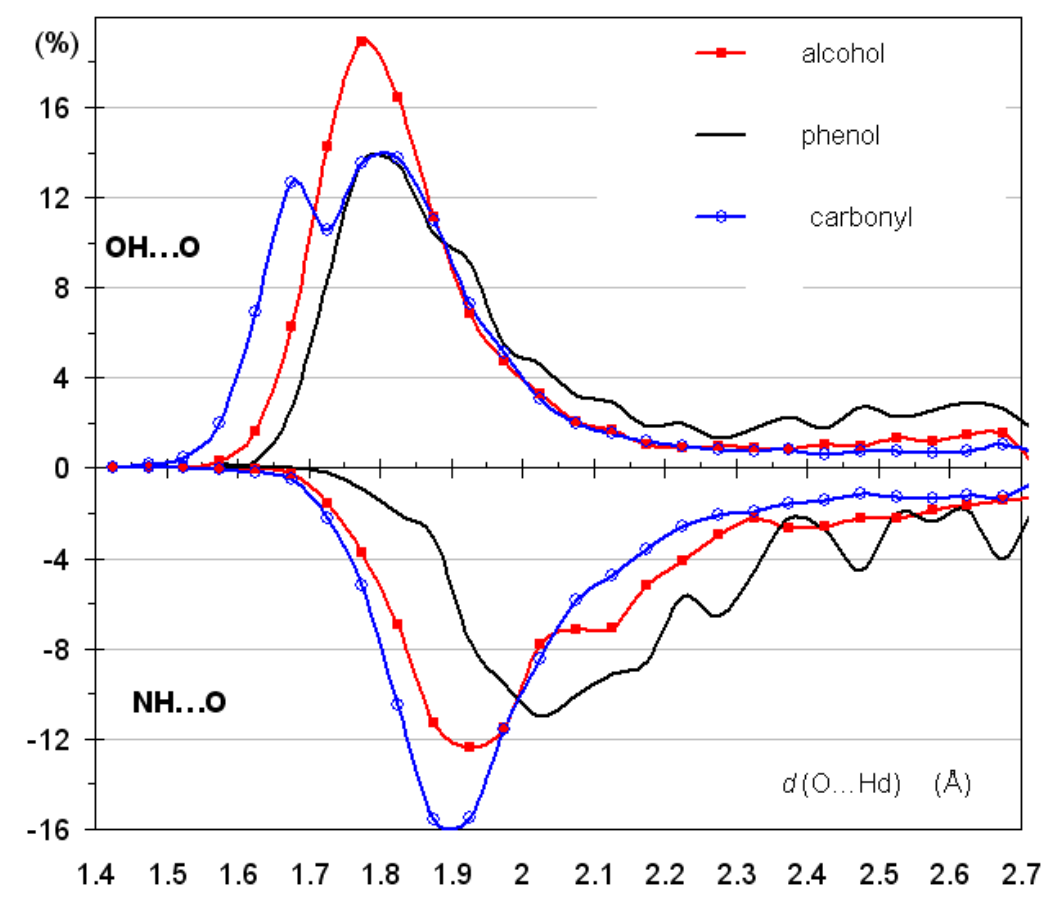

Figure 10.

Frequency (\%) of $\mathrm{O} . . . \mathrm{H}_{\mathrm{d}}$ distances in hydrogen bonds with $\mathrm{HO}$ (top) and $\mathrm{HN}$ (bottom) donors in alcohols, phenols and carbonyl acceptors. 


\section{Supplementary material.}

\section{Figure S1}

Example of another deformation of the experimental electron density in the lone pairs plane of a phenol group found in $( \pm)-8$ 'benzhydryl-ideneamino-1,1'-binaphthyl-2-ol (Farrugia, L. J.; Kocovský, P.; Senn, H. M.; Vyskocil, S. Acta Crystallogr. 2009. B65, 757-769.)

Contours $\pm 0.05 \mathrm{e} / \AA^{3}$. positive: solid blue lines. Negative: dashed red lines.

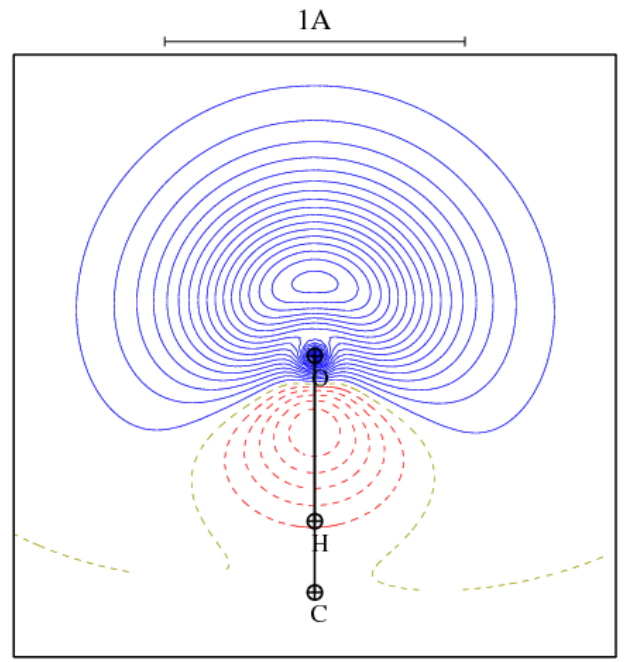




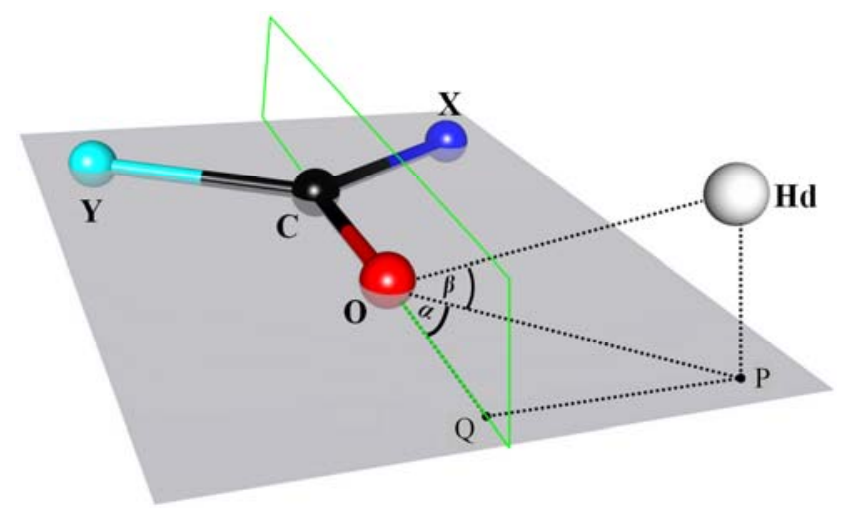

Figure S2: Diagram describing the $\alpha$ and $\beta$ angles obtainment for carbonyl.

$\mathrm{P}$ is the projection of $\mathrm{Hd}$ on the $\mathrm{XYC}=\mathrm{O}$ plane containing the two lone pairs.

$\mathrm{Q}$ is the projection of $\mathrm{H}$ on the $\mathrm{C}=\mathrm{O}$ line.

Distances and angles used from the Cambridge Structural Database:

$-\mathrm{OH}_{\mathrm{d}}=$ distance $(\mathrm{O} \ldots \mathrm{Hd})$

- $\mathrm{PH}_{\mathrm{d}}=$ distance $(\mathrm{Hd}, \mathrm{COH}$ plane $)$

- $\left(\mathrm{CO}, \mathrm{OH}_{\mathrm{d}}\right)$ angle

Derived geometric data.

$\mathrm{OP}=\left(\mathrm{OH}_{\mathrm{d}}^{2}-\mathrm{pH}_{\mathrm{d}}{ }^{2}\right)^{1 / 2}$

$\mathrm{OQ}=\cos \left(\mathrm{CO}, \mathrm{OH}_{\mathrm{d}}\right) * \mathrm{OH}_{\mathrm{d}}$

$\alpha=\operatorname{arccosine}(\mathrm{OQ} / \mathrm{OP})$

$\beta=\operatorname{arcsine}\left(\mathrm{PH}_{\mathrm{d}} / \mathrm{OH}_{\mathrm{d}}\right)$ 


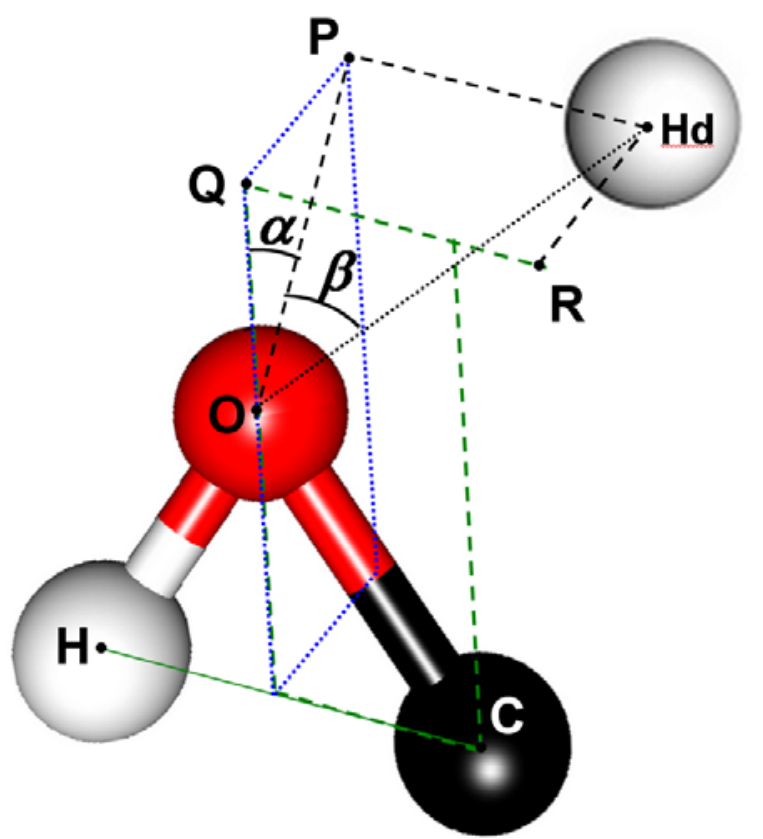

Figure S3:

Diagram describing the $\alpha$ and $\beta$ angles obtainment for hydroxyl group C-O-H.

$\mathrm{R}$ is the projection of $\mathrm{H}_{\mathrm{d}}$ on the $\mathrm{COH}$ plane.

$\mathrm{Q}$ is the projection on the inner bisecting line.

$\mathrm{P}$ is the projection on the $\mathrm{COH}$ bisecting plane containing the two electron lone pairs.

Distances and angles used from the Cambridge Structural Database:

- angles $\mathrm{COH}_{\mathrm{d}} \mathrm{COH}$

- distances $\mathrm{OH}_{\mathrm{d}} \mathrm{CH}_{\mathrm{d}} \mathrm{CO}$

- distance to $\mathrm{COH}$ plane: $\mathrm{PQ}=\mathrm{RH}_{\mathrm{d}}$

\section{Derived geometric data:}

$\mathrm{OR}=\left(\mathrm{OH}_{\mathrm{d}}^{2}-\mathrm{RH}_{\mathrm{d}}^{2}\right)^{1 / 2}$ as $\mathrm{ORH}_{\mathrm{d}}=90^{\circ}$

$\mathrm{CR}=\left(\mathrm{CH}_{\mathrm{d}}^{2}-\mathrm{RH}_{\mathrm{d}}^{2}\right)^{1 / 2}$ as $\mathrm{CRH}_{\mathrm{d}}=90^{\circ}$

Al-Kashi Theorem: $\mathrm{COP}=\operatorname{arcosine}\left(\mathrm{CO}^{*} \mathrm{CO}+\mathrm{OR} * \mathrm{OR}-\mathrm{CR} * \mathrm{CR}\right) /(\mathrm{CO} * \mathrm{OR})$

$\mathrm{COQ}=180-\mathrm{COH} / 2$ as $\mathrm{OQ}$ is bisecting triangle $\mathrm{COH}$.

$\mathrm{COR}+\mathrm{ROQ}=\mathrm{COQ} \quad$ addition of angles

Then $\mathrm{ROQ}=\mathrm{COQ}-\mathrm{COR}=180-\mathrm{COH} / 2-\mathrm{COR}$

$\mathrm{QR}=\mathrm{OR} * \sin (\mathrm{ROQ}), \mathrm{QR}=\mathrm{PH}_{\mathrm{d}}$ is the distance to the electron lone pairs plane

$\mathrm{OQ}=\left(\mathrm{OR}^{2}-\mathrm{QR}^{2}\right)^{1 / 2}$ as $\mathrm{OQR}=90^{\circ}$

$\beta=\operatorname{arcsine}\left(\mathrm{PHd} / \mathrm{OH}_{\mathrm{d}}\right) \quad \alpha=\arctan (\mathrm{PQ} / \mathrm{OQ})$ 


\section{TOC Figure}

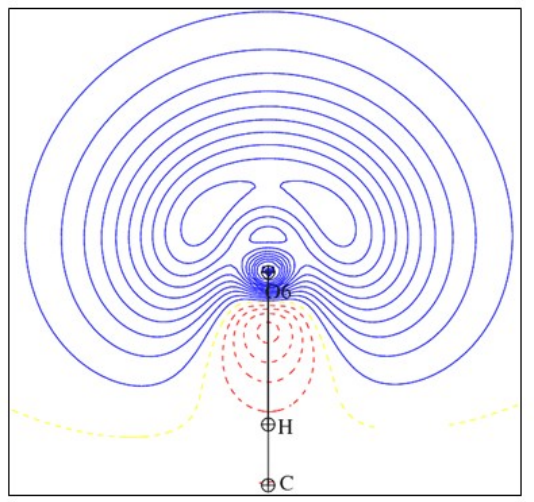

phenols

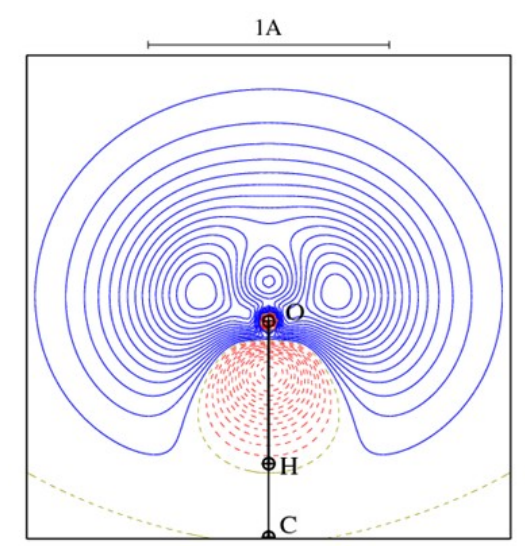

alcohols

Synopsis: Deformation of the electron density in the lone pairs plane of phenols and alcohols obtained from theoretical calculations lead to different hydrogen bonding patterns. 